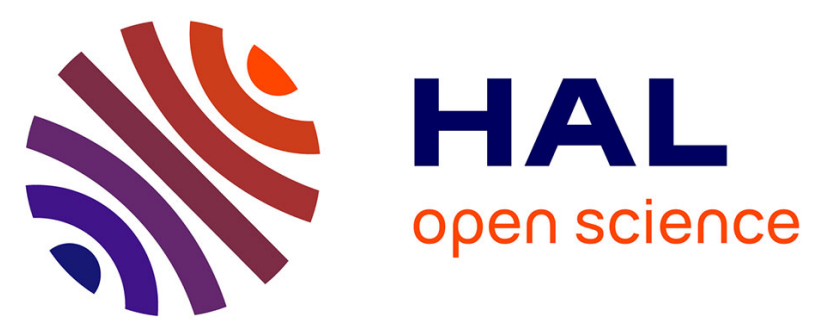

\title{
Deciphering the demographic history of allochronic differentiation in the pine processionary moth Thaumetopoea pityocampa
}

Raphaël Leblois, Mathieu Gautier, Audrey Rohfritsch, Julien Foucaud, Christian Burban, Maxime Galan, Anne Loiseau, Laure Sauné, Manuela Branco, K. Gharbi, et al.

\section{To cite this version:}

Raphaël Leblois, Mathieu Gautier, Audrey Rohfritsch, Julien Foucaud, Christian Burban, et al.. Deciphering the demographic history of allochronic differentiation in the pine processionary moth Thaumetopoea pityocampa. Molecular Ecology, 2018, 27 (1), pp.264-278. 10.1111/mec.14411 . hal02626319

\section{HAL Id: hal-02626319 \\ https://hal.inrae.fr/hal-02626319}

Submitted on 11 Jun 2021

HAL is a multi-disciplinary open access archive for the deposit and dissemination of scientific research documents, whether they are published or not. The documents may come from teaching and research institutions in France or abroad, or from public or private research centers.
L'archive ouverte pluridisciplinaire HAL, est destinée au dépôt et à la diffusion de documents scientifiques de niveau recherche, publiés ou non, émanant des établissements d'enseignement et de recherche français ou étrangers, des laboratoires publics ou privés. 


\section{THE UNIVERSITY of EDINBURGH}

\section{Edinburgh Research Explorer \\ Deciphering the demographic history of allochronic differentiation in the pine processionary moth Thaumetopoea pityocampa}

Citation for published version:

Leblois, R, Gautier, M, Rohfritsch, A, Foucaud, J, Burban, C, Galan, M, Loiseau, A, Sauné, L, Branco, MDO, Gharbi, K, Vitalis, R \& Kerdelhué, C 2017, 'Deciphering the demographic history of allochronic differentiation in the pine processionary moth Thaumetopoea pityocampa', Molecular Ecology.

https://doi.org/10.1111/mec.14411

\section{Digital Object Identifier (DOI):}

$10.1111 /$ mec. 14411

Link:

Link to publication record in Edinburgh Research Explorer

Document Version:

Peer reviewed version

Published In:

Molecular Ecology

\section{General rights}

Copyright for the publications made accessible via the Edinburgh Research Explorer is retained by the author(s) and / or other copyright owners and it is a condition of accessing these publications that users recognise and abide by the legal requirements associated with these rights.

\section{Take down policy}

The University of Edinburgh has made every reasonable effort to ensure that Edinburgh Research Explorer content complies with UK legislation. If you believe that the public display of this file breaches copyright please contact openaccess@ed.ac.uk providing details, and we will remove access to the work immediately and investigate your claim. 


\section{Deciphering the demographic history of allochronic differentiation in the}

\section{pine processionary moth Thaumetopoea pityocampa}

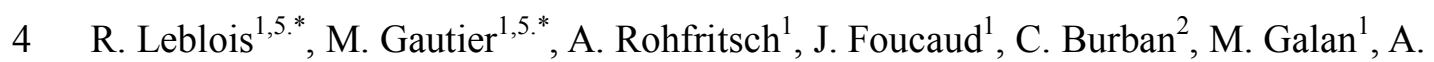

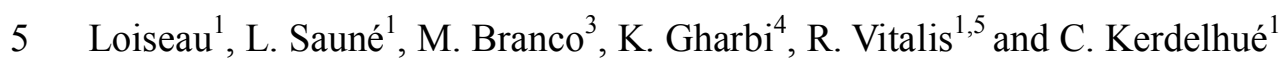

\section{$6 \quad$ Full postal addresses}

7 1. CBGP, INRA, CIRAD, IRD, Montpellier SupAgro, Univ. Montpellier, 755 avenue du

8 Campus Agropolis, CS 300 16, F-34988 Montferrier sur Lez cedex, France

9 2. INRA, UMR1202 BIOGECO (INRA - Université de Bordeaux), 69 Route d'Arcachon, F-

1033612 Cestas cedex, France

11 3. Centro de Estudos Florestais (CEF), Instituto Superior de Agronomia (ISA), University of

12 Lisbon, Lisbon, Portugal

13 4. Edinburgh Genomics, School of Biological Sciences, University of Edinburgh, Edinburgh, 14 EH9 12 3JT, UK

15 5. Institut de Biologie Computationnelle (IBC), Université de Montpellier, 95 rue de la

16 Galera, 34095 Montpellier, France

$17 *$ equal author contributions

Keywords (4-6): population genomics, RAD-sequencing, demographic inference, detection of selection, pine processionary moth, phenology

Name, address, fax number and email of corresponding author

Carole Kerdelhué, INRA, UMR CBGP, 755 avenue du Campus Agropolis, CS 300 16. F-

25 Carole.Kerdelhue@inra.fr

27 Running title: Demographic history of an allochronic population 


\section{Abstract}

29 Understanding the processes of adaptive divergence, which may ultimately lead to speciation, 30 is a major question in evolutionary biology. Allochronic differentiation refers to a particular

31 situation where gene flow is primarily impeded by temporal isolation between early and late 32 reproducers. This process has been suggested to occur in a large array of organisms, even 33 though it is still overlooked in the literature. We here focused on a well-documented case of 34 incipient allochronic speciation in the winter pine processionary moth Thaumetopoea 35 pityocampa. This species typically reproduces in summer and larval development occurs 36 throughout autumn and winter. A unique, phenologically shifted population (SP) was 37 discovered in 1997 in Portugal. It was proved to be strongly differentiated from the sympatric 38 "winter population" (WP), but its evolutionary history could only now be explored. We took 39 advantage of the recent assembly of a draft genome and of the development of pan-genomic 40 RAD-seq markers to decipher the demographic history of the differentiating populations and 41 develop genome scans of adaptive differentiation. We showed that the SP diverged relatively 42 recently, i.e. few hundred years ago, and went through two successive bottlenecks followed 43 by population size expansions, while the sympatric WP is currently experiencing a population 44 decline. We identified outlier SNPs that were mapped onto the genome, but none were 45 associated with the phenological shift or with subsequent adaptations. The strong genetic drift 46 that occurred along the SP lineage certainly challenged our capacity to reveal functionally 47 important loci. 


\section{INTRODUCTION}

49 Ecological speciation in sympatry, the process by which adaptation to contrasting ecological conditions drives the divergence of co-occurring populations, has received growing attention in the last 12 years (Rundle \& Nosil, 2005). The fate of diverging populations maintaining a certain level of gene flow, and the conditions in which speciation can still occur are central questions in evolutionary biology (Smadja \& Butlin, 2011). A mechanism possibly causing sympatric speciation is allochronic differentiation, which occurs when differences in breeding time within a species lead to temporal assortative mating and limit gene flow between early and late reproducers (Alexander \& Bigelow, 1960). Isolation-by-time can further lead to adaptation-by-time (Hendry \& Day, 2005) when divergent selection operates between contrasting environmental conditions encountered at the different breeding times. This process remains largely unexplored in the literature, but has been suggested to occur in a large array of organisms such as plants (Devaux \& Lande, 2008; Savolainen et al., 2006; Weis et al., 2005), birds (Friesen et al., 2007), fishes (Limborg, Waples, Seeb, \& Seeb, 2014), corals (Rosser, 2015, 2016) or insects (Santos, Burban, et al., 2011; Sota et al., 2013; Yamamoto \& Sota, 2009, 2012; Yamamoto, Beljaev, \& Sota, 2016). Many more examples probably remain to be discovered, and only 9 study cases were identified in a recent review of 200 papers as examples of "true allochronic speciation" (Taylor \& Friesen, 2017). To go beyond the description of such case studies and disentangle the evolutionary scenarios underlying allochronic differentiation, much remains to be done; in particular, the initial reduction of migration rate between the diverging populations and the underlying genomic mechanisms remain to be explored in most cases.

The recent advent of high-throughput genomic techniques as well as statistical advances for 
analysing large-scale datasets have opened unprecedented opportunities to address ecological,

72

73

74

evolutionary and genetic questions in non-model organisms (Hasselmann, Ferretti, \& Zayed, 2015). Genome-wide data have been proven to be powerful for estimating the age of demographic events (McCoy, Garud, Kelley, Boggs, \& Petrov, 2014), retrieving fine-scale population genetic structures (Szulkin, Gagnaire, Bierne, \& Charmantier, 2016), and identifying phylogeographic patterns (Derkarabetian, Burns, Starrett, \& Hedin, 2016). More, even if studying wild populations of non-model organisms is still a major challenge, population genomic approaches have allowed identification of genomic regions underlying phenotypic characteristics or traits involved in local adaptation (e.g., Berdan, Mazzoni, Waurick, Roehr, \& Mayer, 2015; Guo, DeFaveri, Sotelo, Nair, \& Merilä, 2015; Hohenlohe, 2014). Here, we used population genomics in a non-model insect species to disentangle the evolutionary scenario of allochronic differentiation, followed by adaptation to new environmental conditions.

We focused on one of the few cases identified by Taylor and Friesen (2017) as a welldocumented example of "true incipient allochronic speciation", namely the pine processionary moth Thaumetopoea pityocampa (Dennis \& Schiffermüller). This species is a well-studied pest of pine trees over the Mediterranean basin. Its caterpillars bear urticating hair, causing public and animal health concern (Battisti, Holm, Fagrell, \& Larsson, 2011; Battisti, Larsson, \& Roques, 2017; Rodríguez-Mahillo et al., 2012). Briefly, T. pityocampa reproduces in summer and larval development occurs through autumn and winter all over its range. Reproduction immediately follows adult emergence, as adults have a very limited lifespan of 1-2 days. In 1997, a population of T. pityocampa showing a shift in phenology (reproduction in spring and larval development in summer) was discovered in the Mata Nacional de Leiria (MNL) in Portugal, where it co-occurred with individuals following the typical biological 
95 cycle (Pimentel et al., 2006; Santos et al., 2007). This unique shifted population is known as 96 the "Summer Population" (SP) as opposed to all other known populations that are referred to as "Winter Populations" (WPs), in relation to the development time of the conspicuous larvae. The SP was initially restricted to a small area of the Mata Nacional, and has been slowly expanding along the coast since then (Godefroid et al., 2016). Strikingly, all larval stages of the SP develop under radically different environmental conditions compared to the typical

101 WPs, experiencing much higher temperatures that were so far supposed to be lethal to early

102 larval stages (Huchon \& Démolin, 1970; Santos, Paiva, Tavares, Kerdelhué, \& Branco, 2011).

103 Understanding the scenario of this divergence is thus of interest in the context of current 104 climate warming.

105 Previous studies have brought significant preliminary knowledge about the genetic and 106 ecological characteristics of the peculiar SP. Analysis of a fragment of the mitochondrial COI 107 gene and of the ITS1 region showed a high sequence similarity between the SP and the 108 sympatric WP, which suggested a local origin of the SP, while microsatellites revealed a high 109 differentiation between the SP and all studied Iberian populations (Santos, Burban, et al., 110 2011; Santos et al., 2007). Moreover, a recent study showed that some individuals belonging 111 to the SP genetic cluster emerge during the WP reproductive season, and are referred to as 112 "LateSP individuals" (Burban et al., 2016). This study also documented signs of rare 113 hybridization between the two allochronic populations. Consistently, hybrids between SP and

114 WP individuals could be obtained in laboratory conditions, and the time of adult emergence (a 115 proxy for breeding time) was shown to be highly heritable (Branco, Paiva, Santos, Burban, \& 116 Kerdelhué, 2017). These patterns suggested that the SP originated from the WP, following a 117 phenological shift of a few individuals, and that gene flow between the SP and the WP is now 118 highly reduced but not absent. Yet, the population genetic data relied on a limited number of 
119 microsatellite markers, and did not allow us to characterize the successive stages of the 120 divergence between the SP and the WP.

121 The objectives of the present work were to uncover major characteristics of this prime 122 example of allochronic differentiation and significantly move towards the fulfilment of the 123 criteria proposed by Taylor and Friesen (2017) by deciphering the evolutionary history of the 124 SP and characterizing its different stages. In particular, we aimed at (i) inferring the timing of 125 the divergence, (ii) measuring the migration rate between diverging populations at different 126 stages to determine if the differentiation occurred in the presence or absence of gene flow; 127 (iii) determining the extent of population size changes, in particular to decipher if the SP 128 experienced a strong bottleneck during the primary divergence step; and (iv) characterizing 129 genomic regions possibly involved in the phenological shift and subsequent adaptations. To 130 achieve these aims, we took advantage of RAD-seq technology (Baird et al., 2008; Davey \& 131 Blaxter, 2011) and the recent release of a first draft genome for T. pityocampa (Gschloessl et 132 al., Submitted) to obtain a large number of informative loci genotyped in the SP and in two 133 WPs occurring in the same region. We used these loci to explore complex demographic

134 scenarios including drift, migration, and variation in population size, and to perform genome135 wide scans for signatures of selection. We could thereby successfully disentangle the main 136 characteristics of the on-going allochronic differentiation process.

\section{Materials ANd Methods}

\section{Biological material}

140 A total of 180 individuals (adult or larvae) of $T$. pityocampa were collected in Portugal 
141 between May 2008 and September 2010 following Santos, Burban, et al. (2011). These

142 individuals originated from three distinct populations or sampling sites: two were collected in 143 the MNL $\left(39^{\circ} 47^{\prime} \mathrm{N} 8^{\circ} 58^{\prime} \mathrm{W}\right)$ and corresponded to the Winter and Summer populations from

144 Leiria (referred to as LWP and LSP), and one winter population was collected in the Setubal

145 peninsula, near Apostiça $\left(38^{\circ} 34^{\prime} \mathrm{N} 9^{\circ} 07^{\prime} \mathrm{W}\right)$, ca. $150 \mathrm{~km}$ south from Leiria, at the same 146 elevation and longitude, and was hereafter denoted as AWP. All individuals were sampled 147 from the host plant Pinus pinaster Aiton.

148 Forty L5 larvae (i.e., $5^{\text {th }}$ larval stage) belonging to the AWP were collected in December 2010; 14940 males, 10 females and 20 L5 larvae belonging to the LWP were sampled in 2008-2010 and 15060 males and 10 females belonging the LSP were sampled in $2008-2010$. For the LSP and 151 LWP, we used two sub-samples in each case. The first one included individuals assigned to 152 the Winter or the Summer population based on the phenology observed in the field following 153 Santos, Burban, et al. (2011) ( $n=40$ for each population, sub-samples referred to as LSP1 and

154 LWP1). The second sub-sample gathered males caught with pheromone traps and previously 155 genotyped using 17 microsatellite loci, from which we excluded the individuals assigned as 156 LateSP, F1 and F2 following Burban et al. (2016); these sub-samples $(n=30$ in each 157 population) will be referred to as LSP2 and LWP2. The exact sampling design is described in 158 Table 1.

\section{RAD-sequencing and SNP calling}

$161 \quad$ RAD-libraries

162 We carried out RAD tag sequencing (Baird et al., 2008) using both individual DNA and 163 population pools of DNA. Individual data were used in combination with the pools to explore 7 
164 the possible causes of the somewhat unexpected results yielded from the LWP1 pool (see

165 Results). In total, we constructed six Pst $\mathrm{I}$-digested paired-end (PE) RAD libraries as 166 described in Gautier et al. (2013).

167 Twenty LSP1 (10 males and 10 females) and 20 LWP1 (10 males and 10 females) samples 168 were barcoded and processed individually in libraries \#1 to \#3 (RAD Ind-Seq using 40 169 barcodes in total, see Table 1). The DNAs of each of the three sampled populations (all the 40 170 LSP1, all the 40 LWP1 and all the 40 AWP individuals respectively) were pooled and each 171 population pool was barcoded with three different barcodes (9 barcodes in total, library \#4).

172 The RAD libraries \#1 to \#4 were then combined and PE sequenced $(2 \times 101 \mathrm{bp})$ on two 173 Illumina HiSeq2000 lanes in the Edinburgh Genomics facility.

174 To replicate the experiment using only individuals genetically assigned to the LSP and LWP 175 clusters following Burban et al. (2016), we further constructed 1 LSP2 and 1 LWP2 RAD 176 libraries. Library \#5 was constructed using 20 LWP2 males individually barcoded and a pool 177 of all the 30 LWP2 DNAs that was identified with ten different barcodes. Finally, library \#6 178 was the counterpart of library \#5 for the LSP2 batch. Libraries \#5 and \#6 were each PE 179 sequenced $(2 \times 101 \mathrm{pb})$ on a single Illumina HiSeq2000 lane on The Edinburgh Genomics 180 facility.

\section{Bioinformatic analyses}

183 Reads were first demultiplexed according to their barcode into individual and pool sequences 184 using the default options of the process_radtags program of the STACKS package (version 185 0.99994) (Catchen, Amores, Hohenlohe, Cresko, \& Postlethwait, 2011; Catchen, Hohenlohe, 
186 Bassham, Amores, \& Cresko, 2013), including $-q$ to remove poor quality reads. PCR 187 duplicates were further discarded using the clone filter program (STACKS v0.99994). The 188 remaining reads were trimmed by removing the first 5 bases and keeping the next 90 bases for 189 reads 1 and keeping the first 95 bases for reads 2 . The reads originating from the same 190 population identified with different barcodes or from the same individuals run on different 191 lanes were merged to increase coverage. We decided to discard three LSP1 and two LWP1 192 individuals from further analyses because their final coverage was too low, hence resulting in 19375 genotyped individuals. The number of remaining PE reads for the Ind-Seq datasets varied 194 from 996,796 to $20,480,652$ with a total of ca. 304 millions $(111,015,950 ; 81,905,824$; $19566,817,320$ and 44,207,850 PE reads for the LSP1; LWP1; LWP2 and LSP2 individuals, 196 respectively). Similarly, ca. 300 millions of PE reads were kept for the Pool-Seq datasets $197(59,692,064 ; 86,867,660 ; 91,755,446 ; 37,102,870$ and $23,485,726$,PE reads for the AWP; 198 LSP1; LWP1; LSP2 and LWP2 pools, respectively). RADseq PE reads were then mapped 199 against the indexed Tpit-SP V1 assembly (Gschloessl et al., Submitted) using the bwa aln and 200 bwa sampe commands of the BWA 0.6.2 program (Li \& Durbin, 2009) with default options to 201 generate bam files for each of the 75 remaining individuals (38 LWP, i.e., 18 LWP1 +20 202 LWP2; and 37 LSP, i.e., 17 LSP1 + 20 LSP2) and the 5 pool samples (Table 1). Between $20356.11 \%$ and $67.39 \%$ RAD sequences were mapped and properly paired onto the genome for 204 the different datasets (mean insert size: $286 \mathrm{bp}$ ).

Generation of the Ind-Seq SNP dataset (gIS)

207 The RAD Ind-Seq bam files were processed using the mpileup command of SAMTOOLS 208 0.1.19 (Li et al., 2009) and the same default options as above to obtain LWP and LSP mpileup 
209 files. SNP and genotype calling were then performed separately for each of these two files

210 using the bcftools view command and the resulting vcf files were merged using the vcf-merge

211 program from the VCFTOOLS 0.1 .12 package (Danecek et al., 2011) after filtering variants

212 using the vefutils.pl varFilter command from the SAMTOOLS suite with default options and -

213 w 5 -d 200. Because of the high heterogeneity in the observed within-SNP and within-

214 individual read coverages, we performed additional filtering steps to obtain a genotyping

215 dataset as comprehensive as possible. First, all the genotypes with a read coverage DP $<5$ or

216 DP $>1,000$ or a Phred quality GQ $<20$ were treated as missing data. The resulting number of 217 genotype calls varied between 7,272 and 180,600 (with a median of 38,130). We thus decided

218 to focus on the 40 individuals (28 LSP, i.e., 16 LSP1 + 12 LSP2; and 12 LWP, i.e., 10 LWP1 +

2192 LWP2) with more than 35,000 genotype calls. We then discarded all the SNPs that were

220 called on less than $90 \%$ of these 40 individuals leading to a total of 6,488 remaining SNPs.

221 The resulting Ind-Seq genotyping dataset - hereafter referred to as gIS - had the following

222 characteristics: (i) the individual genotyping call rate varied between $83.6 \%$ and $99.9 \%$ with a

223 median equal to $96.3 \%$; (ii) the individual mean read coverage varied between 10.8 and 72.1

224 with a median equal to 16.1; (iii) the SNP genotyping call rate varied between $92.5 \%$ and

$225100 \%$ with a median equal to $95.0 \%$; and (iv) the SNP minor allele frequency varied between

$2260.012 \%$ and $0.5 \%$ with a median equal to $0.14 \%$.

227

228 Generation of the Pool-Seq SNP datasets (rPS and pPS)

229 The five RAD Pool-Seq bam files were processed using the mpileup command of SAMTOOLS

230 with default options and $-d 5000-q$ 20. The resulting file was further processed using a

231 custom awk script to compute read counts for each alternative base after discarding bases with 
232 a BAQ quality score $<25$. A position was then considered as variable if (i) it had a coverage

233 of more than 20 and less than $c_{i}^{(\max )}$ reads in each population $i$, where $c_{i}^{(\max )}$ represented the

$23495^{\text {th }}$ percentile of the coverage of all positions for population $i$; (ii) only two different bases

235 were observed across all the five pools; and (iii) the minor allele was represented by at least

236 one read in two different pool samples.

237 The final data read count for the Pool-Seq dataset - hereafter referred to as the rPS dataset -

238 consisted of 58,210 SNPs with mean (median; max) coverage equal to $34.96(32 ; 67)$ for the

239 LWP2 pool; $53.71(50 ; 105)$ for the LSP2 pool; $76.21(72 ; 164)$ for the AWP pool; 122.9 (116;

240 244) for the LWP1 pool; and $124.6(121 ; 253)$ for the LSP1 pool, respectively.

242 For applications requiring allele count data (joint PCA of individual and Pool-Seq data, 243 computation of the SFS, see below), we used the following approach. Let $a_{i j}$ represent the 244 number of reads of the reference allele and $\mathrm{c}_{i j}$ the coverage for SNP $i$ in population (pool) $j$ 245 with haploid sample size $n_{j}$. We further denote similarly $y_{i j}$ the allele count for the reference 246 allele in the sample and $n_{i j}$ the haploid sample size $\left(n_{i j} \leq n_{j}\right)$ for SNP $i$ in population (pool) $j$. 247 The pPS dataset consists of the $y_{i j}$ 's and $n_{i j}$ 's, which were computed as follows:

i) if $c_{i j} \leq n_{j}$ then $\hat{n}_{i j}=c_{i j}$ and $\hat{y}_{i j}=a_{i j}$

ii) if $c_{i j}>n_{j}$ then $\hat{n}_{i j}=n_{j}$ and

ii.1) if $a_{i j}=0$ or $a_{i j}=c_{i j}$ then $\hat{y}_{i j}=a_{i j}$;

$$
\text { ii.2) if } 0<a_{i j}<c_{i j} \text { then } \hat{y}_{i j}=\left(n_{j}-1\right) \wedge\left(1 \vee\left[n_{j} \times\left(a_{i j} / c_{i j}\right)\right]\right)
$$

252 where $\wedge$ and $\vee$ stand for the maximum and the minimum, respectively. Note that formally ii)

253 provides the maximum likelihood estimate of the $y_{i j}$ 's under the assumption that the $a_{i j}$ 's 254 follow a binomial distribution $a_{i j} \sim \operatorname{Bin}\left(y_{i j} / n_{j} . n_{i j}\right)$. This approximation thus amounts in 11 
255 assuming equal contribution of each individual of the pool to the Pool-Seq read data.

257 Population genetic diversity and structure

258 Estimation of $F_{\mathrm{ST}}$ from Pool-Seq data

259 Pairwise and across populations $F_{\mathrm{ST}}$ were estimated using the estimator by Weir and

260 Cockerham (1984) from the pPS data set. Even though this standard estimator was developed

261 to measure differentiation from allele count data and therefore should be used cautiously

262 when considering Pool-Seq data, the inherent biases are expected to be limited here given the

263 haploid pool size, sequencing coverage and level of differentiation of the populations under

264 study (Hivert, Gautier, \& Vitalis, pers. comm.).

265 Estimation and visualisation of the scaled covariance matrix of the population allele

266 frequencies

267 To further assess the overall structuring of genetic diversity, we estimated the scaled 268 covariance matrix of allele frequencies $(\Omega)$ across the five samples using the software 269 BAYPASS (Gautier, 2015) with default options. When applied to read count data (rPS data), 270 the Bayesian model underlying BAYPASS provides an accurate estimate of $\Omega$ by integrating 271 over the unobserved allele count estimation. An eigenvalue decomposition of the resulting $\Omega$

272 matrix was further performed using the $\mathrm{R}$ function $s v d($ ) to represent its major axis of 273 variation. This latter approach amounts to performing a PCA that accounts rigorously for the 274 specificities of the Pool-Seq data in the estimation of the covariance matrix. 
Joint Principal Component Analyses of individual (gIS) and pool-Seq (pPS) data

277 A total of 742 SNPs were in common between the individual gIS and the pPS pool datasets.

278 We combined both datasets to obtain a matrix $\boldsymbol{X}=\left\{x_{i j}\right\}$ (742 SNPs x 45 columns) of allele 279 counts in 40 diploid individual samples $\left(n_{j}=2\right.$ for $j=1$ to 40$)$ and 5 pool samples $280\left(n_{41}=n_{A W P}=80\right.$ and $n_{j}=n_{L S P 1}=n_{L W P 1}=n_{L S P 2}=n_{L W P 2}=60$ for $\mathrm{j}=42$ to 45$)$ resulting in a total 281 of 360 haploid individuals. To account for the differences in sample size, we defined a SNP 282 weight vector $\mathbf{w}=\left\{w_{j}\right\}$ where $w_{j}=1 / 180$ for $j=1$ to $40, w_{41}=w_{A W P}=40 / 180$ and $w_{j}=w_{L S P I}=$ $283 w_{L W P 1}=w_{L S P 2}=w_{L W P 2}=30 / 180$ for $j=42$ to 45 . We then computed the (observed) allele 284 frequencies $f_{i j}=x_{i j} / n_{j}$ for each SNP $i$ and sample $j$, and the overall mean weighted allele 285 frequency $p_{i}=\Sigma_{\mathrm{i}} w_{j} x_{i j}$ for each SNP $i$. Note that $f_{i j}$ was set to $p_{i}$ when $x_{i j}$ was missing. Finally, 286 we computed the standardized allele frequency matrix $\boldsymbol{M}=\left\{m_{i j}\right\}$ where $m_{i j}=\left(x_{i j}-p_{i}\right) /\left(p_{i}\left(1-p_{i}\right)\right)$.

287 A weighted Principal Component Analysis (PCA) was then carried out based on the matrix $\boldsymbol{M}$ 288 and using $\boldsymbol{w}$ as a (row) weight vector with the dudi.pca() function of the R package ade4 289 (Chessel, Dufour, \& Thioulouse, 2004).

\section{Demographic inferences}

\section{Three-population tests of admixture}

$293 \quad F_{3}$ statistics provide a formal test for population admixture in three population trees (Patterson 294 et al., 2012). A significantly negative $F_{3}$ statistics for a $(P 1 ; P 2, P 3)$ configuration supports an 295 admixed origin of population $P 1$ with two ancestral source populations related to $P 2$ and $P 3$ 296 respectively. Note however that the reverse is not necessarily true, e.g., the $F_{3}$ statistics might 297 not be significantly negative in this same configuration if $P 1$ experienced strong drift after the 
298 admixture event. $F_{3}$-based tests were carried out for the possible topologies using the rPS

299 Pool-Seq dataset. To account for the additional sampling level introduced in Pool-Seq 300 experiments (i.e., the sampling of read sequences in the DNA pool), the following unbiased 301 estimator relying on read count data and haploid pool sizes was used:

$$
\widehat{F_{3}}(A,(B, C))=\frac{1}{I} \sum_{i=0}^{I}\left[\widehat{\alpha}_{\imath}(\mathrm{A})+\widehat{\beta}_{l}(\mathrm{~B}, \mathrm{C})-\widehat{\beta}_{\imath}(\mathrm{A}, \mathrm{B})-\widehat{\beta}_{l}(\mathrm{~A}, \mathrm{C})\right]
$$

302 with:

i) $\quad \widehat{\alpha}_{l}(P)=\frac{1}{n_{p}-1}\left(\frac{n_{P} a_{i P}\left(a_{i P}-1\right)}{c_{i P}\left(c_{i P}-1\right)}-\frac{a_{i P}}{c_{i P}}\right)$

304

ii) $\quad \widehat{\beta}_{\iota}(P, Q)=\frac{a_{i P}}{c_{i P}} \frac{a_{i Q}}{c_{i Q}}$

where, for SNP $i, a_{i P}\left(\right.$ resp. $\left.a_{i Q}\right)$ represents the number of reads of the reference allele and $c_{i P}$ (resp. $c_{i Q}$ ) the coverage in population $P$ (resp. $Q$ ) with haploid sample size $n_{p}$. To assess the significance of the departure of each statistic to the null hypothesis $(F=0), Z$-scores were computed as the ratio of the $\widehat{F_{3}}$ mean to its standard deviation both estimated over 5,000 bootstrap samples.

311 Estimation of tree topology and divergence times using KIMTREE

312 For a given tree topology, we estimated divergence times using KIMTREE 1.3 (Gautier \& 313 Vitalis, 2013), with the standard MCMC parameters recommended in the user manual.

314 KIMTREE is a hierarchical Bayesian model where the allele frequencies are modelled along 315 each branch of a population tree using Kimura's time-dependent diffusion approximation for 316 genetic drift (Kimura, 1964). The support of the different topologies was assessed using a 
317 Deviance Information Criterion (DIC) computed as described in Gautier and Vitalis (2013),

318 and up to a constant term, with slight modifications for Pool-Seq data:

$$
\begin{aligned}
D I C=\frac{2}{\mathrm{~T}} \sum_{\mathrm{t}=1}^{\mathrm{T}} \sum_{\mathrm{i}=1}^{\mathrm{I}} \sum_{\mathrm{j}=1}^{\mathrm{J}}-2 \log \left[\left(\begin{array}{c}
c_{i j} \\
a_{i j}
\end{array}\right)\left(\frac{y_{i j}(t)}{n_{j}}\right)^{a_{i j}}\left(1-\frac{y_{i j}(t)}{n_{j}}\right)^{c_{i j}-a_{i j}}\right] \\
-\sum_{\mathrm{i}=1}^{\mathrm{I}} \sum_{\mathrm{j}=1}^{\mathrm{J}}-2 \log \left[\left(\begin{array}{c}
c_{i j} \\
a_{i j}
\end{array}\right)\left(\frac{\widehat{y_{l j}}}{n_{j}}\right)^{a_{i j}}\left(1-\frac{\widehat{y_{l j}}}{n_{j}}\right)^{c_{i j}-a_{i j}}\right]
\end{aligned}
$$

319 where $y_{i j}(t)$ represents the sampled allele count value for SNP $i$ in pool $j$ at the $t^{\text {th }}$ MCMC 320 iteration (out of $T$ ) and $\widehat{y_{l j}}$ the posterior mean of the corresponding allele count computed 321 over the $T$ MCMC samples.

324 To explore more complex demographic scenarios, we analyzed the joint site frequency 325 spectrum (SFS) of the three sampled populations using the approach of Nielsen (2000) 326 implemented in Fastsimcoal2 2.5.2.21 (Excoffier, Dupanloup, Huerta-Sanchez, Sousa, \& 327 Foll, 2013). This approach uses coalescent simulations to infer the likelihood of the observed 328 SFS under any demographic model, and performs well even in situation where the events are recent (Excoffier et al., 2013). The analyses were run on the folded SFS, i.e., using the

330 observed counts of the minor allele, obtained from the pPS datasets of the LSP2, LWP2 and 331 AWP samples (LSP2 and LWP2 were chosen based on the $F_{3}$ statistics, see Result section) 332 with a pool size of 30 , i.e., the haploid size of the smallest pool. We directly estimated the 333 scaled parameters of the models in a coalescent or a diffusion time scale (i.e., $2 N \mu, 2 N m, T / N$ 334 and $\mu T$ ) and then inferred the canonical parameters (divergence time $T$ expressed in 
335 generations, migration rates, and population size expressed in number of genes $N$, i.e., twice

336 the number of diploid individuals) using the mutation rate $\mu=2.910^{-9}$ mutations per

337 generation per SNP, as recently estimated for the Lepidoptera Heliconius melpomene

338 (Keightley et al., 2015). Note that this estimate of mutation rate is lower than that of

339 Drosophila melanogaster (Haag-Liautard et al., 2007), and is expected to be more appropriate

340 for our Lepidoptera model species. Estimated divergence times thus tend to be older than if

341 we had used the Drosophila mutation rate.

342 We first considered a simple model of pure divergence and drift (DivDrift), which

343 corresponds to the KIMTREE model, for the three possible topologies. This analysis allowed us

344 to compare inferences of tree topologies and scaled divergence times obtained with two

345 different methods, and therefore to check that the FASTSIMCOAL algorithm performed well

346 when used with the pPS data set. We could identify the most likely topology in this simple

347 model and then further increase step-by-step the complexity of the scenario. First we

348 incorporated past fluctuations in population size (DivDriftVar), second we allowed migration

349 between all populations (DivDriftMig), and third we considered both variations in population

350 size and migration (DivDriftVarMig). All models were compared using the Akaike

351 Information Criteria (AIC). Inferences of the canonical and/or scaled parameters were only

352 considered for the simple DivDrift model for comparison with KIMTREE, and for the best 353 supported model. Finally, 95\% confidence intervals (CI) were built using parametric bootstrap 354 as explained in Excoffier et al. (2013). Detailed inference settings and parameter ranges

355 explored for each analysis are described in Appendix S1 and Table S1 (Supporting 356 information). 


\section{Whole genome scans for adaptive differentiation using SELESTIM and BAYPASS}

359 Whole genome scans for adaptive differentiation were carried out by looking for overly 360 differentiated SNPs using both SELESTIM version 1.1.3 (Vitalis, Gautier, Dawson, \& 361 Beaumont, 2014) and BAYPASs version 2.1 (Gautier, 2015) that are both handling Pool-Seq 362 data. SELESTIM is based on a diffusion approximation for the distribution of allele frequencies 363 in a subdivided population, which explicitly accounts for selection. In particular, SELESTIM 364 assumes that each and every locus is targeted by selection to some extent, and estimates the 365 strength of selection at each locus in each population. For each analysis, twenty-five short 366 pilot runs (1,000 iterations each) were set to adjust the proposal distributions for each model 367 parameter and, after a 100,000 burn-in period, 100,000 updating steps were performed with a 368 thinning interval of 40 steps. Candidate markers under selection were selected on the basis of 369 the distance between the posterior distribution for the locus-specific coefficient of selection 370 and a "centering distribution" derived from the distribution of a genome-wide parameter that 371 accounts for the among-locus variation in selection strength. SELESTIM uses the Kullback372 Leibler divergence (KLD) as a distance between the two distributions, which is calibrated 373 using simulations from a posterior predictive distribution based on the observed data (Vitalis 374 et al., 2014). Hereafter, we report candidate markers with KLD values above the 99.9\% 375 quantile of the so-obtained empirical distribution of KLD.

376 In BAYPASS, we identified candidate markers using the $X t X$ differentiation measure (Günther $377 \&$ Coop, 2013). This metrics might be viewed as a SNP-specific $F_{\text {ST }}$ that explicitly corrects 378 for the scaled covariance of population allele frequencies (matrix $\Omega$ ), making it robust to the 379 unknown demographic history relating the populations. The $X t X$ was estimated using default 380 options of BAYPASS. Pairwise correlations of the $X t X$ estimates across ten independent runs 381 were all found to be above 0.995 demonstrating the stability of the estimates. As described in 17 
382 Gautier (2015), the $X t X$ was calibrated based on a posterior predictive distribution obtained by

383 analyzing a pseudo-observed dataset of 250,000 SNPs generated under the inference model

384 with hyper-parameters fixed to their respective posterior means as estimated from the analysis

385 of the original data. Hereafter, we report candidate markers with $X t X$ values above the $99.9 \%$

386 quantile of the so-obtained empirical distribution of $X t X$. To identify the population of origin

387 of the signal for overly differentiated SNPs, we examined the posterior means of the

388 standardized population allele frequencies defined for each SNP $i$ and population $j$ as:

$$
\boldsymbol{X}_{i}=\left\{x_{i j}\right\}_{j \in(1, \ldots, J)}=\frac{1}{\sqrt{\pi_{\mathrm{i}}\left(1-\pi_{\mathrm{i}}\right)}} \Gamma^{-1} \boldsymbol{\alpha}_{\mathrm{i}}
$$

389 where $\boldsymbol{\alpha}_{\mathrm{i}}$ represents the (unobserved) vector of population allele frequencies, $\pi_{\mathrm{i}}$ represents the

390 across population allele frequency, and $\Gamma$ the Cholesky decomposition matrix of $\Omega$ (i.e.,

$\left.391 \Omega=\Gamma \Gamma^{\mathrm{T}}\right)$. Although the standardized allele frequencies $\left(x_{i j}\right)$ are expected to be independent

392 and identically normally distributed under the null model (Günther \& Coop, 2013), the

393 Bayesian (hierarchical) model-based estimation procedure leads to shrink their estimated

394 posterior mean. As a result, they were each calibrated as the $X t X$, i.e., using their respective

395 empirical distribution obtained from the analysis of the pseudo-observed dataset described 396 above.

397

398 RESULTS

\section{Population genetic diversity and structure}

400 The multi-locus $F_{\mathrm{ST}}$ across the five samples was equal to 0.259 while pairwise population $F_{\mathrm{ST}}$

401 varied from 0.038 for the (LSP1;LSP2) pair to 0.374 for the (AWP;LSP2) pair (Table 2). The 
402 LWP1 and LWP2 samples appeared differentiated, with a pairwise $F_{\text {ST }}$ equal to 0.068 .

403 Nevertheless, both the LWP1 and LWP2 samples were found closer to the AWP $\left(F_{\mathrm{ST}}\right.$ equal to 4040.095 and 0.125 for the (AWP;LWP1) and (AWP;LWP2) pairs, respectively) than to the LSP 405 ( $F_{\mathrm{ST}}$ ranging from 0.302 to 0.368 depending on the sub-samples representing LSP and LWP).

406 We estimated the scaled covariance matrix of allele frequencies $\Omega$ across the five samples 407 using BAYPASS, and performed an eigenvalue decomposition of that matrix, which results in a 408 principal component analysis accounting for the specificities of the Pool-Seq data. As shown 409 in Fig. 1A, the first axis of variation (PC1) accounted for $93.5 \%$ of the total genetic variation 410 and separated the samples according to the phenology of their underlying population (i.e., 411 LSP1 and LSP2 vs. LWP1, LWP2 and AWP). The second axis of variation (PC2) that only 412 accounted for $4.17 \%$ of the total variation was associated with a geographic gradient since it 413 separated the Leiria samples (LSP1, LSP2, LWP1 and LWP2) from the Apostiça sample 414 (AWP). Importantly, the coordinates of both the LSP1 and LWP1 samples on PC1 were found 415 closer to the origin than their corresponding LSP2 and LWP2 counterparts. This result 416 suggests the presence of LateSP individuals and/or hybrids in either LSP1, LWP1 or both.

417 This latter result was supported by the joint analysis of a subset of the Pool-Seq data together 418 with the 28 LSP and 12 LWP genotyped individuals that had more than 35,000 genotype calls. 419 Fig. 1B shows the first factorial plan of a joint PCA performed on 742 SNPs that were in 420 common between the Pool-Seq dataset (pPS) and the individual dataset (gIS). Although the 421 number of SNPs was lower and the data for pool samples were projected onto their 422 corresponding haploid sample size, the overall picture displayed in Fig. 1B was qualitatively 423 similar to that of Fig. 1A. Interestingly, based on their coordinate on PC1, at least 3 out of the 42412 genotyped LWP1 individuals appeared to be either LateSP or introgressed individuals.

425 When ignoring these 3 individuals, the coordinates of LWP individuals on PC1 were very 19 
426 close to that of the LWP2 pool sample. Conversely, the PC1 coordinates for all LSP

427 individuals remained close to those of both the LSP1 and LSP2 pool samples. All results 428 (PCA and BAYPASS) thus suggested a higher variability across the LWP samples than across 429 the LSP ones. They also revealed that some LateSP and introgressed individuals were 430 included in the LWP1 pool that contained individuals that were only phenotypically assigned 431 to their "phenological" population.

\section{Demographic inference}

$F_{3}$-based tests of admixture

435

436

Three-population tests were carried out for all the 30 possible configurations among the five pool samples (Table S2, Supporting information). Six configurations resulted in significant negative $F_{3}$-statistics. They corresponded to the four configurations that tested the LWP1 sample against another WP sample (AWP or LWP2) and a LSP sample (either LSP1 or LSP2) as source populations: (i) (LWP1; AWP, LSP1) with $Z=-9.02$; (ii) (LWP1; AWP, LSP2) with $Z=-9.45$; (iii) (LWP1; LSP1, LWP2) with $Z=-17.8$; and (iv) (LWP1; LSP2, LWP2) with $Z=-11.7$. This result confirmed the inclusion of LateSP individuals in the LWP1 pool, as suggested by the PCA. The two other configurations displaying significantly negative $F_{3^{-}}$ statistics tested the LSP1 sample against the LSP2 sample and either the LWP1 or AWP as samples representative of the WP: (i) (LSP1; AWP, LSP2) with $Z=-4.00$; (ii) (LSP1; LSP2, LWP1) with $Z=-3.57$. On the contrary, considering the LWP2 sample as representative of the LWP did not result in a significantly negative $F_{3}$ (Table S2, Supporting information). In that case, the signal of admixture might be hidden by the stronger drift in LSP1, the $F_{\mathrm{ST}}$ of the (LWP2, LSP1) pair being higher than that of the (LWP1, LSP1) pair. We here recall that the 
449 results of the $F_{3}$ test should be interpreted only when significant. As both the PCA and $F_{3^{-}}$ 450 statistics suggested that the LWP1 pool probably contained LateSP individuals, we further 451 used only the LSP2 and LWP2 samples as representing the LSP and LWP to infer the 452 demographic history of the LSP.

455 We first ran KIMTREE on the Pool-Seq rPS data to compare the four possible topologies 456 relating the AWP, LSP (using LSP2 sample) and LWP (LWP2 sample) under a pure-drift 457 model of divergence (Fig. 2). The DIC gave the strongest support to the (LSP,(AWP,LWP)) 458 tree (Fig. 2). Interestingly, the branch length relating the LSP to the root population (ancestral 459 to the winter and summer populations) revealed a strong signature of drift $\left(\tau_{L S P}=0.383\right)$.

460 We then analyzed the joint SFS of the three populations using the estimated allele count data 461 pPS for different demographic models. Considering a simple model of divergence and drift 462 (DivDrift), the best-supported tree according to the AIC corresponded to the best supported 463 tree obtained with KIMTREE (Table S3, Supporting information). In the following steps, we 464 thus only considered the topology (LSP,(LWP,AWP)) (Table 3). SFS analyses under this 465 model lead to precise estimates of scaled parameters such as population size ratios $\left(N_{\mathrm{P}} / N_{\mathrm{WP}}\right.$ $466=7.9[5.4 ; 9.9]$ and $\left.N_{\mathrm{WP}} / N_{\mathrm{LSP}}=26[17 ; 35]\right)$, and of the four scaled divergence times for the 467 different branches of tree, that can be directly compared to those inferred from KIMTREE and 468 appear to be highly consistent (Fig. 2). Indeed, we estimated $T_{\mathrm{P}} / N_{\mathrm{LSP}}=0.35[0.34 ; 0.37]$ (to 469 compare with $\tau_{L S P}=0.383$ in Fig. 2); $T_{W P} / N_{\text {LWP }}=0.085[0.081 ; 0.092]$ (to compare with $\tau_{L W P}$ $470=0.099$ in Fig. 2); $T_{\mathrm{WP}} / N_{\mathrm{AWP}}=0.089[0.081 ; 0.092]$ (to compare with $\tau_{A W P}=0.117$ in Fig. 2); 471 and $\left(T_{\mathrm{P}}-T_{W P}\right) / N_{\mathrm{WP}}=0.11[0.094 ; 0.12]$ (to compare with $\tau_{P 4}=0.107$ in Fig. 2 ). This overall 21 
472 good agreement between the KIMTREE and SFS analyses suggest that estimating the SFS from 473 the inferred allele counts (pPS dataset) provides robust results (KIMTREE analyses being 474 based on the read count rPS dataset).

475 We further investigated more complex models by including migration between the 476 populations (DivDriftMig model), variation in population sizes (DivDriftVar model) or both 477 (DivDriftVarMig model). Comparison of AICs for these four demographic models showed 478 that the data strongly supported the DivDriftVarMig model detailed in Fig. 3 (Table S4, 479 Supporting information). Most of the 24 canonical parameters of this latter model, i.e., all 480 population sizes and divergence times as well as some migration rates, were inferred with 481 good precision (Table 3). The few exceptions concerned some migration rates for which CIs 482 were relatively broad.

483 Overall, the SFS analyses suggested that the ancestral SP and WP diverged relatively recently, 484 ca. 560 generations ago (with a confidence interval CI ranging from 448 to 2280), both 485 experiencing a concomitant bottleneck. Then the ancestral SP experienced a first expansion, 486 followed by a second bottleneck ca. $69(\mathrm{CI}=35-216)$ generations ago, and a second strong 487 expansion until present. From the ancestral WP, LWP and AWP diverged ca. 207 generations 488 ago $(\mathrm{CI}=95-526)$. Note that age estimates depend on the mutation rate used, which is lower 489 in Heliconius butterflies (Keightley et al., 2015) than in Drosophila (Haag-Liautard et al., 490 2007). LWP recently experienced a relatively severe contraction while AWP showed an 491 expansion event. Accordingly, negative growth rates (corresponding to expansions in the 492 coalescence analyses) were inferred for all but the LWP. Finally, inferred migration rates were 493 relatively large for the pairs (AWP,LWP) and (LSP,LWP), with especially large values for the 494 migration from LWP to AWP and to a lesser extent from LSP to LWP. On the contrary, 
495 inferred migration rates were lowest for the pair (LSP,AWP) as well as for the migration from 496 SP to WP, i.e., the ancestral populations.

497

498 Genome-scan for adaptive differentiation

499 We performed genome scans for adaptive differentiation across the three population samples 500 (AWP, LWP2 and LSP2) using both the SELESTIM and BAYPASS software packages. Out of 501 the 54,040 analyzed SNPs (4,170 SNPs from the original rPS dataset were discarded since 502 monomorphic in the three analyzed population pools), 12 were found outlier with SELESTIM 503 and 73 with BAYPASS; 11 were in common between the two analyses (Fig. 4; Fig. S1 and 504 Table S5, Supporting information). However, we found no locus presumably involved in the 505 phenological shift or subsequent ecological adaptation in the LSP. Indeed, among the outlier 506 SNPs, none displayed extreme value for either the population-specific coefficient of selection 507 estimated with SELEstiM, or the standardized allele frequencies estimated with BAYPAsS in 508 the LSP2 sample only. Instead, most outliers displayed outstanding differentiation in both the 509 LWP and LSP (data not shown).

510 We then mapped the outlier SNPs onto the recently obtained draft genome (Gschloessl et al.,

511 Submitted) and used the associated gene prediction and transcriptomic resources to annotate 512 the SNPs which fell within or near $(<2,000 \mathrm{pb})$ a potential gene. The 74 SNPs mapped to 63 513 different scaffolds; 7 of these SNPs were located within a gene (5 in introns of 4 different 514 predicted or reconstructed genes, 2 in exons of 2 genes), 7 were located in the vicinity of 5 515 different predicted or reconstructed genes. Only two of the corresponding genes could be 516 annotated, and corresponded to a transcription domain-associated protein of Operophtera 517 brumata and an E3 ubiquitin-protein ligase RFWD2-like of the Pyralidae Amyelois 
518 transitella. These results are detailed in Tables S5 and S6, Supporting information.

519

520

\section{DISCUSSION}

522 In this study, we analyzed an illustrative example of "true allochronic differentiation" (sensu

523 Taylor \& Friesen, 2017) between sympatric populations of the pine processionary moth. Our 524 results allowed us to decipher when and how the primary divergence occurred (bottleneck 525 intensity, levels of gene flow), which allows us to propose hypotheses about the 526 circumstances of the differentiation and the subsequent history of the populations.

528 The primary divergence: a fairly recent allochronic event associated to a strong 529 bottleneck and an abrupt disruption of gene flow

530 Tree-based analyses suggested that the phenologically-shifted SP first diverged from the 531 common ancestor of the two studied WPs, which differentiated more recently from one 532 another. The long branch leading to the SP suggested that this population experienced very 533 strong drift. The model was significantly improved by including changes in population sizes 534 and migration between populations, suggesting that the demographic history associated with 535 the allochronic event is relatively complex. We could infer in detail this evolutionary scenario.

536 The common ancestor of the SP and the WP is supposed to have been present for a long time 537 (estimated to 900,000 years), with large population sizes $\left(10^{5}\right.$ to $10^{6}$ reproducing individuals), 538 which is consistent with the continuous occurrence of the pine processionary moth in the 
539 refugial areas of the Iberian Peninsula during the Ice Ages (Rousselet et al., 2010). The

540 divergence of the SP was estimated to have occurred ca. 560 years ago, and it was associated 541 with a very strong founder event (ancestral population size estimated to a few tens of 542 individuals), while a bottleneck event occurred in the ancestral WP. One of the main questions 543 about sympatric differentiation is to know whether it occurred in the presence or absence of 544 gene flow in the first steps of the divergence, and how migration evolved over time (Powell, 545 Forbes, Hood, \& Feder, 2014; Smadja \& Butlin, 2011). The question of the levels of gene 546 flow can shed light on the differentiation process and impact the possible fate of the diverging 547 populations. In the particular case of allochronic differentiation, the shift in breeding time can 548 occur progressively, an overlap in reproductive times of the incipient populations then 549 maintaining gene flow (with some similarities between isolation-by-distance and isolation-by550 time in this case, see Hendry \& Day, 2005). Conversely, it can also appear as an abrupt 551 phenological change that would immediately disrupt gene flow and lead to an "automatic" 552 complete assortative mating, acting as an "automatic magic trait" sensu Servedio, Doorn, 553 Kopp, Frame \& Nosil (2011). Our results showed that the first step of the differentiation 554 occurred in a context of highly limited gene flow between the ancestral SP and WP (migration 555 rate $10^{-5}$ to $10^{-8}$ ). This corroborates the hypothesis of a sudden event of divergence, resulting 556 in an immediate barrier to gene flow between the two incipient populations.

557 Allochrony can in some situations evolve as a by-product of another primary driver of 558 speciation, such as host plant shift followed by alteration of breeding time to match with the 559 new host's phenology (Powell et al., 2014). It is not possible from our results to rule out the 560 hypothesis that the two populations primarily diverged due to other factors, and that 561 allochrony evolved more recently and would now be the main differentiated trait. On the 562 other hand, no host or habitat change is associated with the differentiation of the SP. The land 25 
563 was once covered by mixed forests and shrubs (AFN - Autoridade Florestal Nacional, 2012),

564 and then sowed with $P$. pinaster during the XIII ${ }^{\text {th }}$ and early $\mathrm{XIV}^{\text {th }}$ century. The divergence of

565 the SP probably occurred after this large afforestation program, which took place ca. 700

566 years ago, when P. pinaster was already predominant in this region. We thus conclude that in

567 the particular case of the pine processionary moth, allochrony can still be hypothesized to be

568 the initial driver of divergence. It is very likely that the periods of adult activity of the two

569 diverging populations did not overlap in the early phases of their differentiation, immediately

570 disrupting gene flow. A scenario of an initial mutation in key genes involved in seasonal

571 rhythms or affecting diapause termination which first occurred by chance and drove the

572 differentiation event in a very limited number of founder individuals can thus be favoured

573 (Schluter, 2009), and would be consistent with the high heritability found in experimental

574 rearing (Branco et al., 2017). This information is crucial for our understanding of the

575 allochronic differentiation process.

576 We obtained a relatively recent estimate of the divergence time, but our results suggest that

577 the SP was already present few hundreds years before its discovery in 1997 (Santos, Burban,

578 et al., 2011; Santos et al., 2007). No mention was found in the historical archives of the Mata

579 Nacional de Leiria (MB, pers. obs.), even though these archives contain much information

580 because the national park has been a major wood production area for more than seven

581 centuries. Yet, it is also possible that the ancestral SP evolved in the same region, but outside

582 the limits of the park, and remained undocumented in historical times. In a recent study,

583 Godefroid and collaborators (2016) showed that the current distribution of the LSP is limited

584 by the high summer temperature occurring elsewhere in Portugal, even though larvae of this

585 population were proved to cope better with higher temperatures than larvae of Portuguese and

586 French WPs (Santos, Paiva, et al., 2011). In the first steps of the differentiation, milder 26 
587 environmental conditions could have favoured the success of the diverging population.

588 Interestingly, a period of colder climate known as the Little Ice Age occurred between years 5891300 and 1900, including in Portugal, bringing favourable climatic conditions (Abrantes et 590 al., 2005; Bartels-Jónsdóttir, Knudsen, Abrantes, Lebreiro, \& Eiríksson, 2006). Other

591 phenotypic trait divergences between the SP and the WP were documented, with obvious

592 adaptations to the environmental changes experienced by the SP eggs and larvae due to the 593 shift in breeding time (Rocha et al., 2017; Santos, Paiva, et al., 2011; Santos, Paiva, Rocha, 594 Kerdelhué, \& Branco, 2013), consistent with the concept of "adaptation-by-time" proposed by 595 Hendry and Day (2005). Whether such phenotypic changes occurred over ca. 500 years or 596 whether they occurred over some tens of generations as previously suggested (Santos, 597 Burban, et al., 2011; Santos et al., 2007), these adaptations can still be considered as rapid.

\section{Recent demographic changes in the diverging population and increased recent gene flow}

600 The best demographic model we obtained further suggested that the SP experienced a recent 601 bottleneck ca. 70 years ago, which reduced the population to a few hundred reproducers at 602 most. The SP then expanded again until its high current population size (between 25,000 and 603100,000 individuals). The cause of this recent and drastic reduction in size is difficult to 604 characterize, and could be due to a local climatic or epidemiological event or to human 605 activities (e.g., local habitat destruction, forest fire, management options). This bottleneck 606 actually coincides with the recent establishment of intensive planning and forest management 607 in the MNL. The first forest plan dates back from 1892 and was intensified during the 1960s, 608 including management by clear-cuts and development of $120 \mathrm{~km}$ of forest roads (AFN 609 Autoridade Florestal Nacional, 2012). This major demographic event is consistent with the 
610 fact that the SP remained undetected in the recent history and was discovered only recently

611 during a very severe and thus conspicuous outbreak in 1997 (Pimentel et al., 2006; Santos et

612 al., 2007). Parallel to the SP history, our model also suggested a complex scenario for the

613 studied WPs. AWP and LWP diverged ca. 200 years ago, with a very strong founder event in

614 Apostiça as the estimated population size reached 43 individuals only. This event could be

615 linked to human activities and to the deforestation process that occurred to provision wood

616 and agricultural goods, which dramatically decreased forest land in the region of Lisbon

617 (Devy-Vareta, 1985). This probably tended to fragment the PPM habitat and strongly reduced

618 its populations in the vicinity of Lisbon. It is worth noting that in the recent years, the

619 population size has strongly increased in Apostiça, which is consistent with the recent

620 afforestation activity, whereas the Leiria WP tended to decrease. Whether the decline of the

621 WP observed in the MNL could be linked to possible competition between the sympatric

622 summer and winter populations should now be tested. Monitoring tools could moreover allow

623 us to determine if this is a long-term trend or if the local LWP would increase again. On the

624 other hand, our results consistently show that AWP was closely related to LWP, and could not

625 be used as an outgroup as we initially planned. A thorough phylogeographic study of

626 Portuguese and/or Iberian populations would now be helpful to understand the genetic

627 structure of populations in this PPM clade (Rousselet et al., 2010) and to develop further

628 demographic analyses.

629 To complete the picture, our results suggested that some gene flow currently occurs between

630 existing populations. Not surprisingly, in the best demographic model, migration rates were

631 maximal between the two WPs but they were also relatively high in both directions between

632 the two sympatric LSP and LWP (ca. $10^{-3}$ ). This is consistent with the recent identification of

633 few hybrid individuals by Burban and collaborators (2016). Interestingly, our results suggest 
634 that the level of gene flow between the sympatric populations is higher today than in earlier 635 stages of differentiation. This could be explained by the recent geographic and demographic 636 expansion observed in the SP, which could have increased the probability of contact and thus 637 introgression between the two populations. We could also hypothesize that plasticity in 638 reproductive time plays a role by allowing some degree of overlap in reproductive time 639 between the two populations, which can possibly vary over time as occurs in some plants 640 (Devaux \& Lande, 2008). Some individuals belonging to the SP but emerging during the LWP 641 reproductive season were recently identified with molecular markers (Burban et al., 2016). 642 Such "LateSP" individuals can only be identified through genotyping, and could also allow 643 some introgression between the two populations. The results further showed that assigning 644 individuals from their phenology alone can lead to erroneous mixing of some LateSP 645 individuals in the LWP1 pool, and that robust results could only be obtained when pooling 646 genetically well-characterized individuals. Preliminary observations suggest that some of 647 these LateSP correspond to the last-emerging SP individuals, i.e., to events at the tail-end of 648 the distribution of SP emergence time in July, during the early WP season. Other LateSP 649 actually emerge very late, after the WP season, and could correspond to a dysfunction in 650 diapause termination (Burban et al., 2016). The origins and fate of these categories of LateSP 651 remain to be studied.

\section{Identifying and interpreting signatures of selection}

654 All of the SNPs identified by BAYPASS and SELESTIM as presumably under selection 655 displayed population-specific signatures associated with both the LSP and the LWP, which did 656 not allow us to clearly identify a pattern linked to the phenotypic evolution of the SP. It is 
657 likely that the strong drift experienced by the SP and the high level of differentiation between 658 the SP and both LWP and AWP $\left(F_{\mathrm{ST}}>0.3\right)$ impedes optimal use of genomic scans of 659 adaptation. A similar challenge in revealing functionally important loci due to a stronger than 660 expected background differentiation was encountered by Lozier, Jackson, Dillon, \& Strange 661 (2016) in their study of Bombus colour patterns. Moreover, even if RAD-seq was proved to be 662 a powerful approach to easily develop population genomic studies for non-model organisms, 663 the technique only allows us to analyze a reduced proportion of the genome, which increases 664 the likelihood of missing the genomic region truly targeted by selection (Lowry et al., 2017; 665 but see McKinney, Larson, Seeb, \& Seeb, 2017). Our study also pointed a major challenge in 666 arthropod genomics, which is the low proportion of functionally annotated genes. We could 667 annotate only two of the genes in the vicinity of the detected candidate SNP, which strongly 668 limits the functional interpretation of the results. Moreover, the draft genome currently 669 available for T. pityocampa has low scaffold sizes (Gschloessl et al., Submitted), which 670 explains why most of the identified SNP were found in different genomic fragments. 671 Improving the genome assembly will greatly increase our analyzing capacities.

\section{Perspectives and future directions}

674 Several studies have recently identified candidate genes involved in circadian and seasonal 675 rhythms and in diapause termination, and their roles and interactions are increasingly 676 understood (Denlinger, 2002; Derks et al., 2015; Wadsworth \& Dopman, 2015). In particular,

677 there is increasing evidence that genes involved in circadian rhythms are also involved in 678 reproductive cycles (Fuchikawa et al., 2010; Levy, Kozak, Wadsworth, Coates, \& Dopman, 679 2015; Ragland, Egan, Feder, Berlocher, \& Hahn, 2011; Ragland \& Keep, 2017). One possible 
680 approach will be to target those genes both to re-sequence them in the SP and WP and 681 possibly identify sequence polymorphisms, and to determine if they are differentially 682 expressed in the allochronic populations at key stages of the development. An alternative 683 approach could be QTL-mapping, which has proved to be a successful strategy in a number of 684 studies (e.g., Alem et al., 2013; Franchini et al., 2014). It is however expected to be tedious in the particular example of the pine processionary moth for which rearing in experimental conditions is a difficult task due to a high mortality, the urticating nature of its larvae, and the obligate one-year generation time (Berardi, Branco, Paiva, Santos, \& Battisti, 2015; Branco et al., 2017; Rocha et al., 2017).

\section{ACKNOWLEDGEMENTS}

691 We thank H. Santos for sampling the PPM individuals analyzed in this paper. We are grateful 692 to B. Gschloessl who facilitated access to the genome assembly and provided the SNP 693 annotations, and to A. Estoup for fruitful discussions in the early steps of the project. The 694 authors also wish to thank Pierre-Alexandre Gagnaire for the RAD adaptors and Hélène 695 Holota from TAGC facility for the Covaris sonication of the RAD libraries.

696 This work was supported by a grant from the French National Research Agency (ANR-10697 JCJC- 1705-01 - GENOPHENO) and by the Institut National de la Recherche Agronomique 698 (GAPP project, INRA AIP BioRessources 2012). Part of this work was carried out with the 699 resources of the INRA MIGALE (http://migale. jouy.inra.fr) and GENOTOUL bioinformatics 700 platforms. We also relied on the HPC of the CBGP and of the Montpellier Bioinformatics

701 Biodiversity (MBB) platform of the LabEx CeMEB (Laboratoire d'Excellence Centre

702 Méditerranéen de l'Environnement et de la Biodiversité), and we benefitted from the technical 31 
assistance of A. Dehne- Garcia. Edinburgh Genomics is funded in part by grants from the UK

Natural Environment Research Council (R8/H10/56) and Medical Research Council

(G0900740). The work in Portugal was partially funded by the FCT national project

UID/AGR/00239/2013.

\section{REFERENCES}

Abrantes, F., Lebreiro, S., Rodrigues, T., Gil, I., Bartels-Jonsdottir, H., Oliveira, P., . . . Grimalt, J. O. (2005). Shallow-marine sediment cores record climate variability and earthquake activity off Lisbon (Portugal) for the last 2000 years. Quaternary Science Reviews, 24, 2477-2494. doi:10.1016/j.quascirev.2004.04.009

AFN - Autoridade Florestal Nacional (2012). Estratégia para a gestão das matas nacionais. Lisboa, Portugal: Relatório Direção Nacional de Gestão Florestal.

Alem, S., Streiff, R., Courtois, B., Zenboudji, S., Limousin, D., \& Greenfield, M. D. (2013). Genetic architecture of sensory exploitation: QTL mapping of female and male receiver traits in an acoustic moth. Journal of Evolutionary Biology, 26(12), 2581-2596. doi: $10.1111 /$ jeb. 12252

Alexander, R. D., \& Bigelow, R. S. (1960). Allochronic speciation in field crickets, and a new species, Acheta veletis. Evolution, 14(3), 334-346.

Baird, N. A., Etter, P. D., Atwood, T. S., Currey, M. C., Shiver, A. L., Lewis, Z. A., . . . Johnson, E. A. (2008). Rapid SNP discovery and genetic mapping using sequenced RAD markers. PLoS ONE, 3(10), e3376. doi:10.1371/journal.pone.0003376

Bartels-Jónsdóttir, H. B., Knudsen, K. L., Abrantes, F., Lebreiro, S., \& Eiríksson, J. (2006). Climate variability during the last 2000 years in the Tagus Prodelta, western Iberian Margin: benthic foraminifera and stable isotopes. Marine Micropaleontology, 59, 83103. doi:10.1016/j.marmicro.2006.01.002

Battisti, A., Holm, G., Fagrell, B., \& Larsson, S. (2011). Urticating hairs in arthropods: their nature and medical significance. Annual Review of Entomology, 56(1), 203-220. doi:10.1146/annurev-ento-120709-144844

Battisti, A., Larsson, S., \& Roques, A. (2017). Processionary moths and associated urtication risk: global change-driven effects. Annual Review of Entomology, 62(1), 323-342. doi:10.1146/annurev-ento-031616-034918

Berardi, L., Branco, M., Paiva, M.-R., Santos, H., \& Battisti, A. (2015). Development time plasticity of the pine processionary moth (Thaumetopoea pityocampa) populations under laboratory conditions. Entomologia, 3(1), 273. doi:10.4081/entomologia.2015.273

Berdan, E. L., Mazzoni, C. J., Waurick, I., Roehr, J. T., \& Mayer, F. (2015). A population genomic scan in Chorthippus grasshoppers unveils previously unknown phenotypic divergence. Molecular Ecology, 24(15), 3918-3930. doi:10.1111/mec. 13276

Branco, M., Paiva, M.-R., Santos, H., Burban, C., \& Kerdelhué, C. (2017). Experimental evidence for heritable reproductive time in 2 allochronic populations of pine processionary moth. Insect Science, 24(2), 325-335. doi:0.1111/1744-7917.12287

Burban, C., Gautier, M., Leblois, R., Landes, J., Santos, H., Paiva, M.-R., . . Kerdelhué, C. 32 
(2016). Evidence for low-level hybridization between two allochronic populations of the pine processionary moth Thaumetopoea pityocampa (Lepidoptera: Notodontidae). Biological Journal of the Linnean Society, 119(2), 311-328. doi:10.1111/bij.12829

Catchen, J., Amores, A., Hohenlohe, P. A., Cresko, W., \& Postlethwait, J. (2011). Stacks: building and genotyping loci de novo from short-read sequences. G3: Genes, Genomes, Genetics, 1, 171-182. doi:10.1534/g3.111.000240

Catchen, J., Hohenlohe, P. A., Bassham, S., Amores, A., \& Cresko, W. A. (2013). Stacks: an analysis tool set for population genomics. Molecular Ecology, 22(11), 3124-3140. doi:10.1111/mec. 12354

Chessel, D., Dufour, A.-B., \& Thioulouse, J. (2004). The ade4 package - I : One-table methods. $R$ News, 4(1), 5-10.

Danecek, P., Auton, A., Abecasis, G., Albers, C. A., Banks, E., DePristo, M. A., . . . 1000 Genomes Project Analysis Group. (2011). The variant call format and VCFtools. Bioinformatics, 27(15), 2156-2158. doi:10.1093/bioinformatics/btr330

Davey, J. W., \& Blaxter, M. L. (2011). RADSeq: next-generation population genetics. Briefings in Functional Genomics, 9(5), 416- 423. doi:10.1093/bfgp/elq031

Denlinger, D. L. (2002). Regulation of diapause. Annual Review of Entomology, 47, 93-122.

Derkarabetian, S., Burns, M., Starrett, J., \& Hedin, M. (2016). Population genomic evidence for multiple Pliocene refugia in a montane-restricted harvestman (Arachnida, Opiliones, Sclerobunus robustus) from the southwestern United States. Molecular Ecology, 25(18), 4611-4631. doi:10.1111/mec. 13789

Derks, M. F. L., Smit, S., Salis, L., Schijlen, E., Bossers, A., Mateman, C., . . Megens, H.-J. (2015). The genome of winter moth (Operophtera brumata) provides a genomic perspective on sexual dimorphism and phenology. Genome Biology and Evolution, 7(8), 2321-2332. doi:10.1093/gbe/evv145

Devaux, C., \& Lande, R. (2008). Incipient allochronic speciation due to non-selective assortative mating by flowering time, mutation and genetic drift. Proceedings of the Royal Society B: Biological Sciences, 275(1652), 2723-2732. doi:10.1098/rspb.2008.0882

Devy-Vareta, N. (1985). Para uma geografia histórica da floresta portuguesa. Revista da Faculdade de Letras-Geografia, I, 47-67.

Excoffier, L., Dupanloup, I., Huerta-Sanchez, E., Sousa, V. C., \& Foll, M. (2013). Robust demographic inference from genomic and SNP data. Plos Genetics, 9(10), e1003905. doi:10.1371/journal.pgen.1003905

Franchini, P., Fruciano, C., Spreitzer, M. L., Jones, J. C., Elmer, K. R., Henning, F., \& Meyer, A. (2014). Genomic architecture of ecologically divergent body shape in a pair of sympatric crater lake cichlid fishes. Molecular Ecology, 23(7), 1828-1845. doi:10.1111/mec. 12590

Friesen, V. L., Smith, A. L., Gomez-Diaz, E., Bolton, M., Furness, R. W., Gonzalez-Solis, J., \& Monteiro, L. R. (2007). Sympatric speciation by allochrony in a seabird. Proceedings of the National Academy of Sciences of the USA, 104(47), 18589-18594. doi:10.1073/pnas.0700446104

Fuchikawa, T., Sanada, S., Nishio, R., Matsumoto, A., Matsuyama, T., Yamagishi, M., .. . Miyatake, T. (2010). The clock gene cryptochrome of Bactrocera cucurbitae (Diptera: Tephritidae) in strains with different mating times. Heredity, 104, 387-392. doi:10.1038/hdy.2009.167

Gautier, M. (2015). Genome-wide scan for adaptive divergence and association with population-specific covariates. Genetics, 201(4), 1555-1579. 
802

803

804

805

806

807

808

809

810

811

812

813

814

815

816

817

818

819

820

821

822

823

824

825

826

827

828

829

830

831

832

833

834

835

836

837

838

839

doi:10.1534/genetics.115.181453

Gautier, M., Foucaud, J., Gharbi, K., Cézard, T., Galan, M., Loiseau, A., . . . Estoup, A. (2013). Estimation of population allele frequencies from next-generation data: pooled versus individual genotyping. Molecular Ecology, 22(14), 3766-3779. doi: $10.1111 / \mathrm{mec} .12360$

Gautier, M., \& Vitalis, R. (2013). Inferring population histories using genome-wide allele frequency data. Molecular Biology and Evolution, 30(3), 654-668. doi:10.1093/molbev/mss257

Godefroid, M., Rocha, S., Santos, H., Paiva, M.-R., Burban, C., Kerdelhué, C., . . Rossi, J.-P. (2016). Climate constrains range expansion of an allochronic population of the pine processionary moth. Diversity and Distributions, 22(12), 1288-1300. doi:10.1111/ddi.12494

Gschloessl, B., Dorkeld, F., Berges, H., Beydon, G., Bouchez, O., Branco, M., . . Kerdelhué, C. (Submitted). Draft genome and reference transcriptomic resources for the urticating pine defoliator Thaumetopoea pityocampa (Lepidoptera: Notodontidae). Molecular Ecology Resources, MER-17-0372.

Günther, T., \& Coop, G. (2013). Robust identification of local adaptation from allele frequencies. Genetics, 195(1), 205-220. doi:10.1534/genetics.113.152462

Guo, B., DeFaveri, J., Sotelo, G., Nair, A., \& Merilä, J. (2015). Population genomic evidence for adaptive differentiation in Baltic Sea three-spined sticklebacks. BMC Biology, 13(1), 19. doi:10.1186/s12915-015-0130-8

Haag-Liautard, C., Dorris, M., Maside, X., Macaskill, S., Halligan, D. L., Charlesworth, B., \& Keightley, P. D. (2007). Direct estimation of per nucleotide and genomic deleterious mutation rates in Drosophila. Nature, 445, 82-85. doi:10.1038/nature05388

Hasselmann, M., Ferretti, L., \& Zayed, A. (2015). Beyond fruit-flies: population genomic advances in non-Drosophila arthropods. Briefings in Functional Genomics, 14(6), 424431. doi:10.1093/bfgp/elv010

Hendry, A. P., \& Day, T. (2005). Population structure attributable to reproductive time: isolation by time and adaptation by time. Molecular Ecology, 14(4), 901-916. doi:10.1111/j.1365-294X.2005.02480.x

Hohenlohe, P. A. (2014). Ecological genomics in full colour. Molecular Ecology, 23(21), 5129-5131. doi:10.1111/mec. 12945

Huchon, H., \& Démolin, G. (1970). La bioécologie de la processionnaire du pin. Dispersion potentielle - Dispersion actuelle. Revue Forestière Française, 22, 220-234.

Keightley, P. D., Pinharanda, A., Ness, R. W., Simpson, F., Dasmahapatra, K. K., Mallet, J., . . . Jiggins, C. D. (2015). Estimation of the spontaneous mutation rate in Heliconius melpomene. Molecular Biology and Evolution, 32(1), 239-243. doi:10.1093/molbev/msu302

Kimura, M. (1964). Diffusion models in population genetics. Journal of Applied Probability, $1,177-232$.

Levy, R. C., Kozak, G. M., Wadsworth, C. B., Coates, B. S., \& Dopman, E. B. (2015). Explaining the sawtooth: latitudinal periodicity in a circadian gene correlates with shifts in generation number. Journal of Evolutionary Biology, 28(1), 40-53. doi:10.1111/jeb.12562

Li, H., \& Durbin, R. (2009). Fast and accurate short read alignment with burrows-wheeler transform. Bioinformatics, 25, 1754-1760. doi:10.1093/bioinformatics/btp324

Li, H., Handsaker, B., Wysoker, A., Fennell, T., Ruan, J., Homer, N., . . . 1000 Genome Project Data Processing Subgroup. (2009). The Sequence Alignment/Map format and 
861

862

863

864

865

866

867

868

869

870

871

872

873

874

875

876

877

878

879

880

881

882

883

884

885

886

887

SAMtools. Bioinformatics, 25(16), 2078-2079. doi:10.1093/bioinformatics/btp352

Limborg, M. T., Waples, R. K., Seeb, J. E., \& Seeb, L. W. (2014). Temporally isolated lineages of pink salmon reveal unique signatures of selection on distinct pools of standing genetic variation. Journal of Heredity, 105(6), 835-845. doi:10.1093/jhered/esu063

Lowry, D. B., Hoban, S., Kelley, J. L., Lotterhos, K. E., Reed, L. K., Antolin, M. F., \& Storfer, A. (2017). Breaking RAD: an evaluation of the utility of restriction site-associated DNA sequencing for genome scans of adaptation. Molecular Ecology Resources, 17(2), 142152. doi:10.1111/1755-0998.12635

Lozier, J. D., Jackson, J. M., Dillon, M. E., \& Strange, J. P. (2016). Population genomics of divergence among extreme and intermediate color forms in a polymorphic insect. Ecology and Evolution, 6(4), 1075-1091. doi:10.1002/ece3.1928

McCoy, R. C., Garud, N. R., Kelley, J. L., Boggs, C. L., \& Petrov, D. A. (2014). Genomic inference accurately predicts the timing and severity of a recent bottleneck in a nonmodel insect population. Molecular Ecology, 23(1), 136-150. doi:10.1111/mec.12591

McKinney, G. J., Larson, W. A., Seeb, L. W., \& Seeb, J. E. (2017). RADseq provides unprecedented insights into molecular ecology and evolutionary genetics: comment on Breaking RAD by Lowry et al. (2016). Molecular Ecology Resources, 17(3), 356-361. doi:10.1111/1755-0998.12649

Nielsen, R. (2000). Estimation of population parameters and recombination rates from single nucleotide polymorphisms. Genetics, 154, 931-942.

Patterson, N., Moorjani, P., Luo, Y., Mallick, S., Rohland, N., Zhan, Y., . . Reich, D. (2012). Ancient admixture in human history. Genetics, 192(3), 1065-1093. doi:10.1534/genetics.112.145037

Pimentel, C., Calvão, T., Santos, M., Ferreira, C., Neves, M., \& Nilsson, J.-Å. (2006). Establishment and expansion of a Thaumetopoea pityocampa (Den. \& Schiff.) (Lep. Notodontidae) population with a shifted life cycle in a production pine forest, CentralCoastal Portugal. Forest Ecology and Management, 233(1), 108-115. doi:10.1016/j.foreco.2006.06.005

Powell, T. H. Q., Forbes, A. A., Hood, G. R., \& Feder, J. L. (2014). Ecological adaptation and reproductive isolation in sympatry: genetic and phenotypic evidence for native host races of Rhagoletis pomonella. Molecular Ecology, 23(3), 688-704. doi:10.1111/mec. 12635

Ragland, G. J., Egan, S. P., Feder, J. L., Berlocher, S. H., \& Hahn, D. A. (2011). Developmental trajectories of gene expression reveal candidates for diapause termination: A key life-history transition in the apple maggot fly Rhagoletis pomonella. Journal of Experimental Biology, 214, 3948-3960. doi:10.1242/jeb.061085

Ragland, G. J., \& Keep, E. (2017). Comparative transcriptomics support evolutionary convergence of diapause responses across Insecta. Physiological Entomology, 42(3), 246256. doi:10.1111/phen. 12193

Rocha, S., Kerdelhué, C., Ben Jamaa, M. L., Dhahri, S., Burban, C., \& Branco, M. (2017). Effect of heat waves on embryo mortality in the pine processionary moth. Bulletin of Entomological Research, 107(5), 583-591. doi:10.1017/S0007485317000104

Rodríguez-Mahillo, A. I., González-Muñoz, M., Vega, J. M., López, J. A., Yart, A., Kerdelhué, C., . . . Moneo, I. (2012). Setae from the pine processionary moth (Thaumetopoea pityocampa) contain several relevant allergens. Contact Dermatitis, 67(6), 367-374. doi:10.1111/j.1600-0536.2012.02107.x

Rosser, N. L. (2015). Asynchronous spawning in sympatric populations of a hard coral reveals cryptic species and ancient genetic lineages. Molecular Ecology, 24, 5006-5019. doi:10.1111/mec. 13372 
888 Rosser, N. L. (2016). Demographic history and asynchronous spawning shape genetic

889

890

891

892

893

894

895

896

897

898

899

900

901

902

903

904

905

906

907

908

909

910

911

912

913

914

915

916

917

918

919

920

921

922

923

924

925

926

927

928

929

930

931

932

933

934

935 differentiation among populations of the hard coral Acropora tenuis in Western Australia. Molecular Phylogenetics and Evolution, 98, 89-96. doi:10.1016/j.ympev.2016.02.004

Rousselet, J., Zhao, R., Argal, D., Simonato, M., Battisti, A., Roques, A., \& Kerdelhué, C. (2010). The role of topography in structuring the demographic history of the pine processionary moth Thaumetopoea pityocampa (Lepidoptera: Notodontidae). Journal of Biogeography, 37(8), 1478-1490. doi:10.1111/j.1365-2699.2010.02289.x

Rundle, H. D., \& Nosil, P. (2005). Ecological speciation. Ecology Letters, 8, 336-352. doi:10.1111/j.1461-0248.2004.00715.x

Santos, H., Burban, C., Rousselet, J., Rossi, J.-P., Branco, M., \& Kerdelhué, C. (2011). Incipient allochronic speciation in the pine processionary moth Thaumetopoea pityocampa (Lepidoptera, Notodontidae). Journal of Evolutionary Biology, 24(1), 146158. doi:10.1111/j.1420-9101.2010.02147.x

Santos, H., Paiva, M.-R., Rocha, S., Kerdelhué, C., \& Branco, M. (2013). Phenotypic divergence in reproductive traits of a moth population experiencing a phenological shift. Ecology and Evolution, 3(15), 5098-5108. doi:10.1002/ece3.865

Santos, H., Paiva, M.-R., Tavares, C., Kerdelhué, C., \& Branco, M. (2011). Temperature niche shift observed in a Lepidoptera population under allochronic divergence. Journal of Evolutionary Biology, 24(9), 1897-1905. doi:10.1111/j.1420-9101.2011.02318.x

Santos, H., Rousselet, J., Magnoux, E., Paiva, M.-R., Branco, M., \& Kerdelhué, C. (2007). Genetic isolation through time: allochronic differentiation of a phenologically atypical population of the pine processionary moth. Proceedings of the Royal Society of London Series B, 274(1612), 935-941. doi:10.1098/rspb.2006.3767

Savolainen, V., Anstett, M.-C., Lexer, C., Hutton, I., Clarkson, J. J., Norup, M. V., . . Baker, W. J. (2006). Sympatric speciation in palms on an oceanic island. Nature, 441, 210-213. doi:10.1038/nature04566

Schluter, D. (2009). Evidence for ecological speciation and its alternative. Science, 323, 737741. doi:10.1126/science. 1160006

Servedio, M. R., Doorn, G. S. V., Kopp, M., Frame, A. M., \& Nosil, P. (2011). Magic traits in speciation: magic but not rare? Trends in Ecology \& Evolution, 26(8), 389-397. doi:10.1016/j.tree.2011.04.005

Smadja, C. M., \& Butlin, R. K. (2011). A framework for comparing processes of speciation in the presence of gene flow. Molecular Ecology, 20(24), 5123-5140. doi:10.1111/j.1365294X.2011.05350.x

Sota, T., Yamamoto, S., Cooley, J. R., Hill, K. B. R., Simon, C., \& Yoshimura, J. (2013). Independent divergence of 13- and 17-y life cycles among three periodical cicada lineages. Proceedings of the National Academy of Sciences of the USA, 110(17), 69196924. doi:10.1073/pnas. 1220060110

Szulkin, M., Gagnaire, P.-A., Bierne, N., \& Charmantier, A. (2016). Population genomic footprints of fine-scale differentiation between habitats in Mediterranean blue tits. Molecular Ecology, 25(2), 542-558. doi:10.1111/mec.13486

Taylor, R. S., \& Friesen, V. L. (2017). The role of allochrony in speciation. Molecular Ecology 26(13), 3330-3342. doi:10.1111/mec. 14126

Vitalis, R., Gautier, M., Dawson, K. J., \& Beaumont, M. A. (2014). Detecting and measuring selection from gene frequency data. Genetics, 196, 799-817. doi:10.1534/genetics.113.152991

Wadsworth, C. B., \& Dopman, E. B. (2015). Transcriptome profiling reveals mechanisms for the evolution of insect seasonality. The Journal of Experimental Biology, 218(22), 3611- 
936

937

938

939

940

941

942

943

944

945

946

947

948

949

950

951

952

953

954

955

956

957

958

959

960

961

962

963
3622. doi:10.1242/jeb.126136

Weir, B. S., \& Cockerham, C. C. (1984). Estimating F-statistics for the analysis of population structure. Evolution, 38(6), 1358-1370.

Weis, A. E., Winterer, C., Vacher, C., Kossler, T. M., Young, C. A., \& LeBuhn, G. L. (2005). Phenological assortative mating in flowering plants: the nature and consequences of its frequency-dependence. Evolutionary Ecology Research, 7, 161-181. doi:10.1111/j.14209101.2005.00891.x

Yamamoto, S., Beljaev, E. A., \& Sota, T. (2016). Phylogenetic analysis of the winter geometrid genus Inurois reveals repeated reproductive season shifts. Molecular Phylogenetics and Evolution, 94(Pt A), 47-54. doi:10.1016/j.ympev.2015.08.016

Yamamoto, S., \& Sota, T. (2009). Incipient allochronic speciation by climatic disruption of the reproductive period. Proceedings of the Royal Society of London B: Biological Sciences, 276(1668), 2711-2719. doi:10.1098/rspb.2009.0349

Yamamoto, S., \& Sota, T. (2012). Parallel allochronic divergence in a winter moth due to disruption of reproductive period by winter harshness. Molecular Ecology, 21(1), 174183. doi:10.1111/j.1365-294X.2011.05371.x

\section{DATA ACCESSIBILITY}

Read count data for the five pool samples and individual genotyping datasets are provided in Supplementary Table S7

\section{AUTHOR CONTRIBUTIONS}

Conceived and designed the study: M.Gau., C.K., J.F., M.B., K.G. Performed the wet lab experiments: J.F., M.Gal., L.S., A.L., C.B. Analyzed the data: A.R., M.Gau., R.V., R.L., J.F. Wrote the paper: M.Gau., C.K., R.L. All authors read and approved the final manuscript. 


\section{FIGURE LEGENDS}

965 Figure 1: Principal component analysis of gene frequencies across the AWP, LSP1, LSP2, 966 LWP1 and LWP2 pool samples. A) Plot of the pool sample coordinates on the first two axes 967 of variation of $\Omega$, the scaled covariance matrix of allele frequencies across the five pool 968 samples. The matrix $\Omega$ was estimated with BAYPASS (Gautier, 2015) using read count data 969 (rPS) available on 58210 SNPs. B) First factorial plan of the joint PCA performed on the 970 projected allele count data (pPS) for the five pool samples together with genotyping data for 97128 LSP and 12 LWP individuals. The combined dataset consisted of 742 SNPs.

972 Figure 2: Comparisons under a pure-drift divergence model of three bifurcating tree (A-C) 973 and a star phylogeny (D), relating the AWP, LSP (represented by the LSP2 pool sample) and 974 LWP (represented by the LWP2 pool sample) using KIMTREE (Gautier \& Vitalis, 2013). The 975 tree with the highest support (smallest DIC) is represented in red and corresponds to 976 ((AWP,LWP),LSP). For that tree, the posterior mean of the divergence time (measured on a 977 diffusion time scale) is provided for each branch.

978 Figure 3: Graphical representation of the best supported demographic and historical model 979 inferred using the SFS analyses for the three populations AWP, LWP and LSP. Both time and 980 population sizes are represented on a log scale. Inferred parameter values are given in Table 3. 981 SP is the ancestral population of LSP; WP is the ancestral population of AWP and LWP; P is 982 the ancestral population of SP and WP; ANC is the ancestral population of P. All populations 983 have undergone past exponential variations in size, except the ANC population that had a 984 constant size through time. Because of the logarithm representation of time and population 985 sizes, these past exponential population size variations appear linear on the graphic. Arrows 986 represent migration from one population to another, their thickness being proportional to the 987 inferred migration rates.

988 Figure 4: Results of the genome scans for adaptive differentiation performed with SELESTIM 989 and BAYPASS. For each SNP the KLD estimated with SELESTIM that quantifies to which extent 990 the locus-specific coefficient of selection is extreme is plotted against the $X t X$ measure of 991 differentiation estimated with BAYPASS. The horizontal (resp. vertical) dotted line indicates the $9920.1 \%$ significance thresholds for the KLD (resp. XtX) analysis that was determined as the $99399.9 \%$ quantile of an empirical distribution obtained after analyzing a pseudo observed 994 dataset simulated under the SELESTIM (resp. BAYPASS) null model. According to these 995 thresholds, SNPs are displayed in red (outliers based on both the KLD and $X t X$ ), in blue 996 (outlier based on the KLD only), in green (outlier based on the $X t X$ only) or in black (not 997 outlier).

998 


\section{SUPPORTING INFORMATION}

1000 Table S1: Parameter ranges explored in the SFS analyses for the DivDrift and 1001 DivDriftVarMig models.

1002 Table S2: Results of the $F_{3}$-statistics for the 30 possible configurations among the five pool 1003 samples.

1004 Table S3: Comparisons of the three models of pure divergence based on their AIC computed 1005 from SFS analyses. $d$ is the number of parameters of the model, $L$ is the likelihood, AIC is $2 d$ $1006-2 \ln (L), \triangle \mathrm{i}$ is $A I C \mathrm{i}-\min (A I C \mathrm{i})$, and $w_{\mathrm{i}}$ is the model normalized relative likelihood computed 1007 as $\exp (-0.5 \Delta \mathrm{i}) / \Sigma_{\mathrm{k}} \exp (-0.5 \Delta \mathrm{k})$. Parentheses indicate the most recent branching in the tree 1008 going backward in time.

1009 Table S4: Comparisons of the four demographic models analyzed (DivDrift, DivDriftMig, 1010 DivDriftVar, DivDriftVarMig) based on their AIC computed from SFS analyses. For this 1011 table, the population tree considered is always (LSP,(LWP,AWP)). See main text for details 1012 about the different models and Table S3 for details about the notations.

1013 Table S5: Details of the 74 SNPs identified as outliers in SELESTIM and/or BAYPASS analyses. 1014 For each SNP, the scaffold and position are given together with the KLD (SELESTIM analysis) 1015 and XtX (BAYPASS analysis) values. Only values exceeding the $0.1 \%$ significance threshold 1016 are reported for the latter.

1017 Table S6: Details of the 63 scaffolds containing the 74 SNPs identified as outliers in 1018 SELESTIM and/or BAYPASS analyses, position from potentially identified gene when relevant 1019 (within intron, within exon, $<2000 \mathrm{bp}$ ) and annotation when available.

1020 Table S7: Read count data for the five pool samples and individual genotyping datasets

1021 Figure S1: SNP population-specific coefficient of selection and standardized allele 1022 frequencies. For each SNP and population, $\sigma_{\max }$ that corresponds to the largest coefficient of 1023 selection among the two estimated by SELESTIM (one for each allele) is plotted against the 1024 standardized allele frequencies for the reference allele (given in absolute) as estimated by 1025 BAYPASS. For the latter, the vertical dotted line indicates the $99.9 \%$ quantile of the 1026 corresponding empirical distribution (from the pseudo-observed dataset). The colour code 1027 used to represent the SNPs is the same as in Fig. 4: SNPs are displayed in red (outliers based 1028 on both the KLD and $X t X$ ), in blue (outlier based on the KLD only), in green (outlier based on 1029 the $X t X$ only) or in black (not outlier).

1030 Appendix S1: Inference settings for the SFS analyses. 


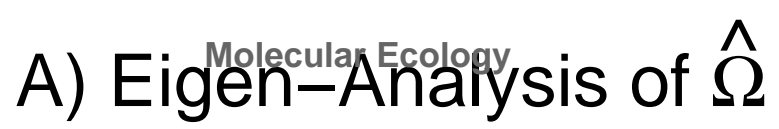

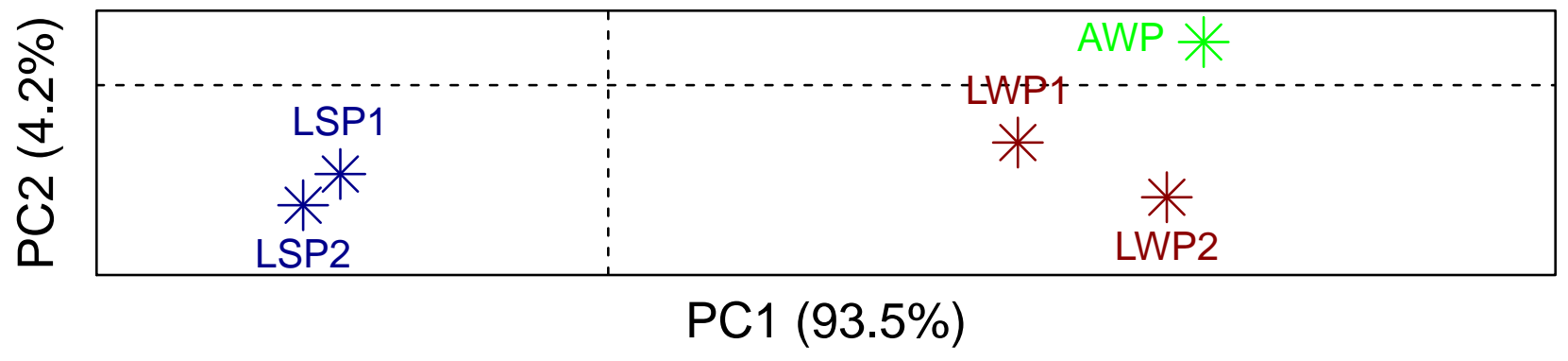

\section{B) Joint PCA of ind. and pool data}

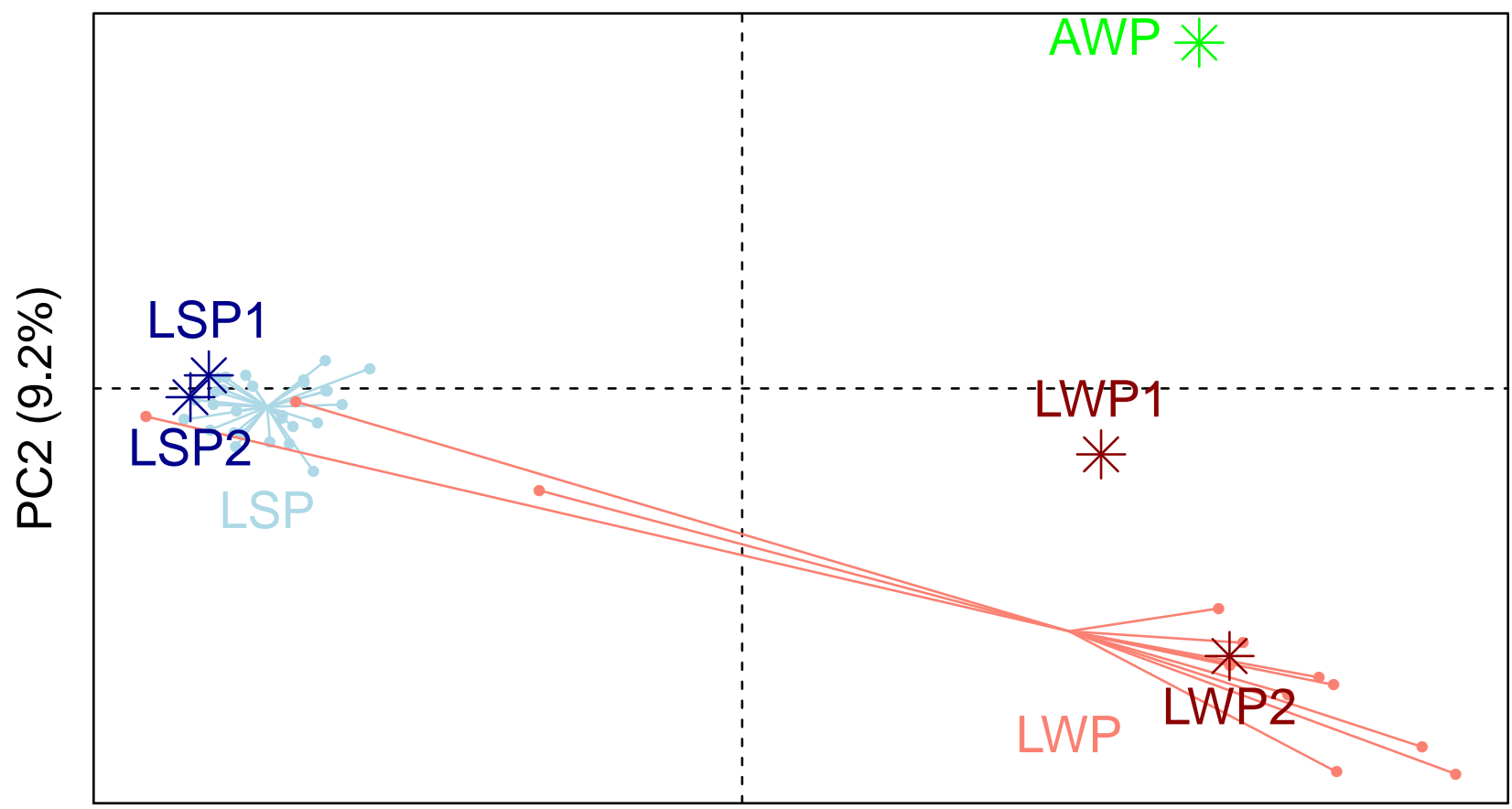

PC1 (38.3\%) 

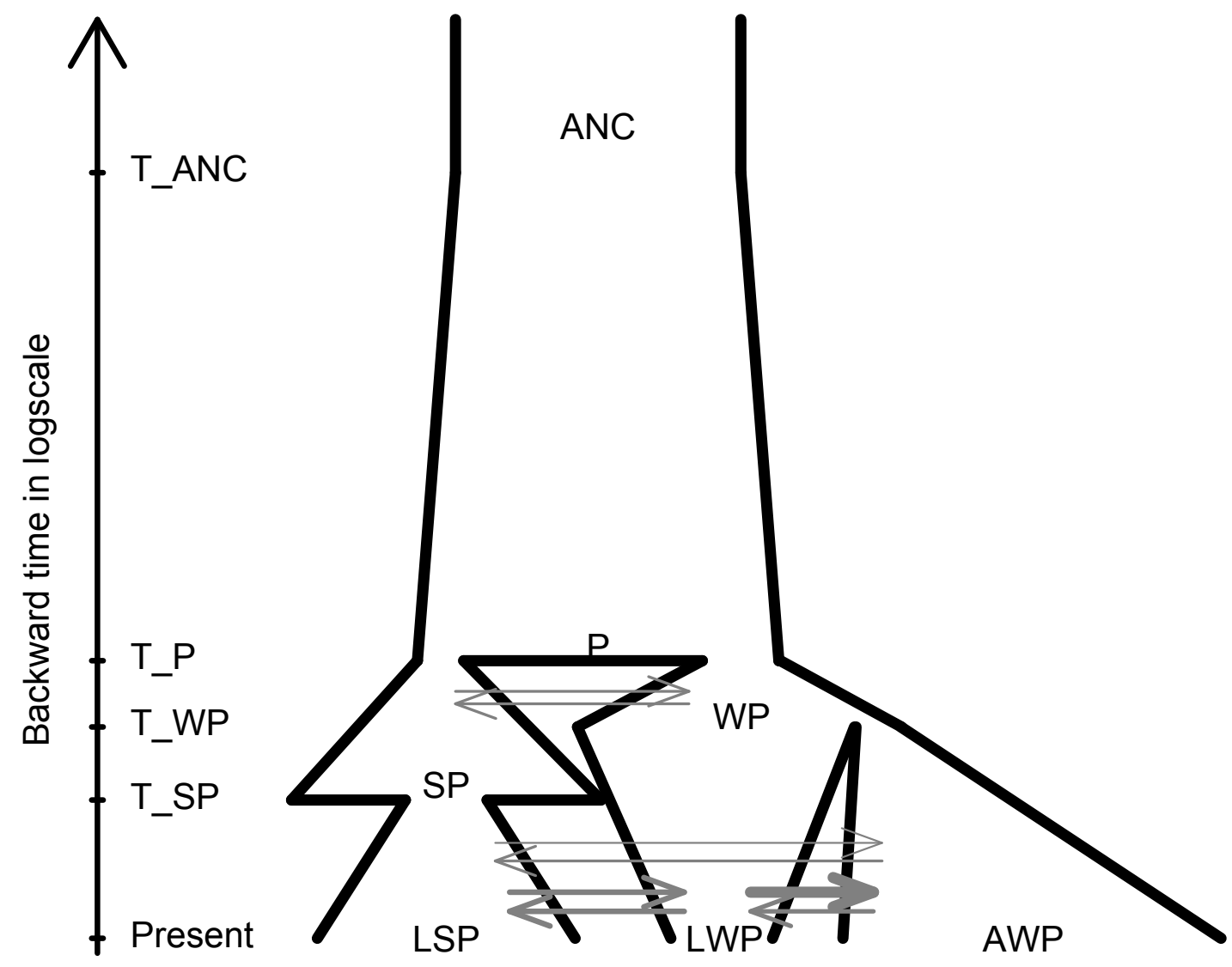

Logarithm of population sizes 


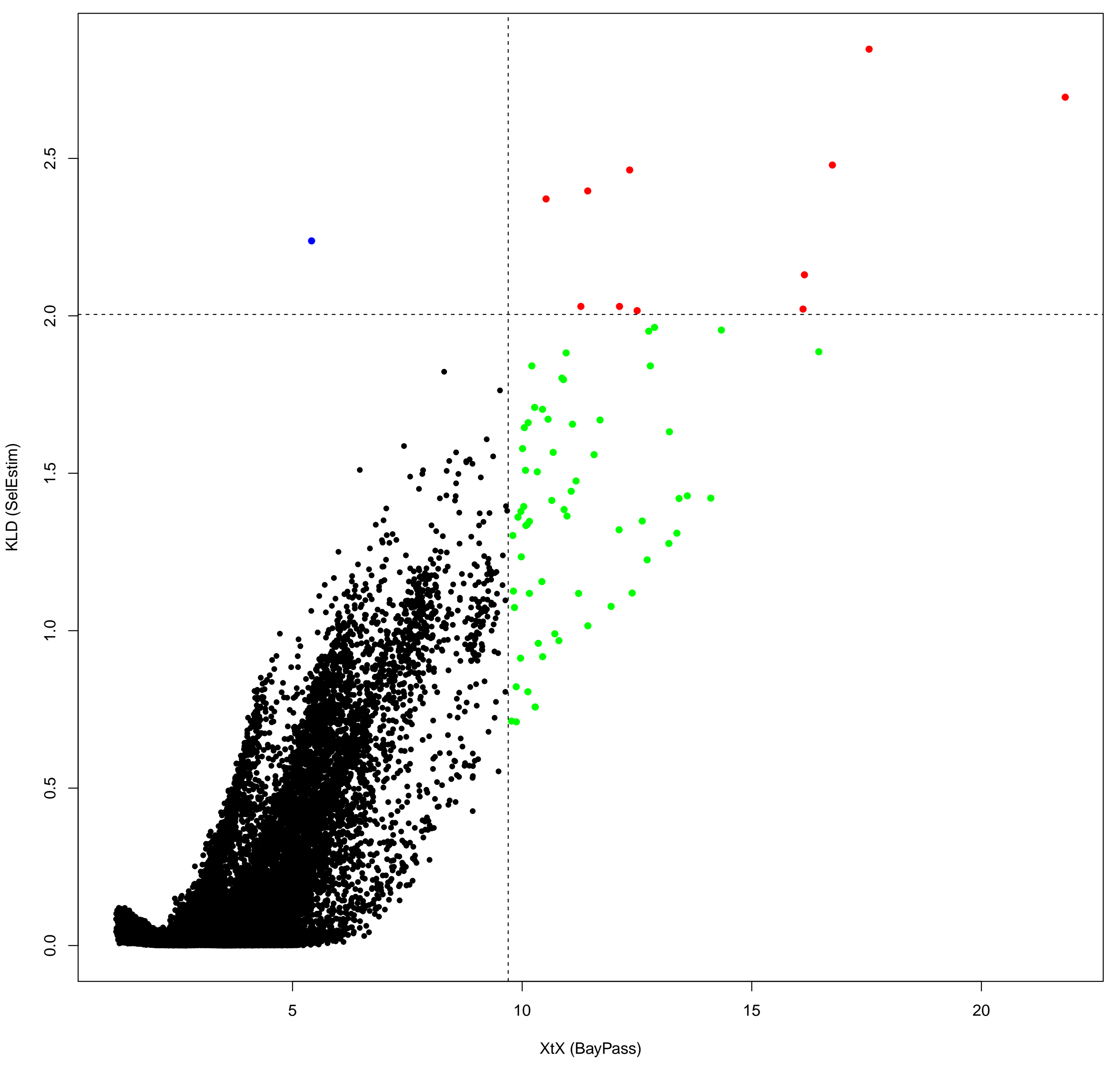


Table 1: Sampling details for the 5 batches of individuals used in the different experiments.

\begin{tabular}{lllll}
\hline Code & Population & \# Individuals from each stage & Dates & Experiment \\
\hline LSP2 & LSP & 20 males & $2008-2010$ & Individual and Pool RAD-seq \\
& LSP & 10 males & $2008-2010$ & Pool RAD-seq \\
LSP1 & LSP & 10 males and 10 females & 2010 & Individual and Pool RAD-seq \\
& LSP & 20 males & 2010 & Pool RAD-seq \\
LWP2 & LWP & 20 males & $2008-2010$ & Individual and Pool RAD-seq \\
& LWP & 10 males & $2008-2010$ & Pool RAD-seq \\
\multirow{2}{*}{ LWP1 } & LWP & 10 males and 10 females & 2010 & Individual and Pool RAD-seq \\
& LWP & 20 L5 larvae & 2010 & Pool RAD-seq \\
AWP & Apostiça & 40 L5 larvae & 2010 & Pool RAD-seq \\
\hline
\end{tabular}


Table 2: pairwise $F_{\mathrm{ST}}$ estimates between the analyzed pools.

\begin{tabular}{lllll}
\hline & AWP & LSP1 & LSP2 & LWP1 \\
\hline AWP & & & & \\
LSP1 & 0.369 & & & \\
LSP2 & 0.374 & 0.038 & & \\
LWP1 & 0.095 & 0.302 & 0.307 & \\
LWP2 & 0.125 & 0.368 & 0.362 & 0.068 \\
\hline
\end{tabular}


Table 3: Parameter point estimates and associated confidence intervals obtained for the best-supported demographic history (DivDriftVarMig with the population tree (LSP,(AWP,LWP))) from the SFS analysis. See Fig. 3 for details.

\begin{tabular}{|c|c|c|c|}
\hline Type of parameter & $\begin{array}{l}\text { Demographic } \\
\text { Parameter }\end{array}$ & "DivDrift" Model & "DivDriftVarMig" Model \\
\hline \multirow{12}{*}{$\begin{array}{l}\text { Effective population } \\
\text { size }\end{array}$} & $\mathrm{N}_{\mathrm{AWP}}(0)$ & $2330\left[2240 ; 1.64 \times 10^{4}\right]$ & $4.40 \times 10^{6}\left[2.85 \times 10^{6} ; 5.16 \times 10^{6}\right]$ \\
\hline & $\mathrm{N}_{\mathrm{LSP}}(0)$ & $2.16 \times 10^{5}\left[2.07 \times 10^{4} ; 4.05 \times 10^{5}\right]$ & $6.63 \times 10^{4}\left[2.48 \times 10^{4} ; 1.63 \times 10^{5}\right]$ \\
\hline & $\mathrm{N}_{\mathrm{LWP}}(0)$ & $3790\left[2930 ; 1.55 \times 10^{4}\right]$ & $293[129 ; 828]$ \\
\hline & $\mathrm{N}_{\mathrm{SP}}\left(\mathrm{T}_{\mathrm{SP}}\right)$ & n.a. & $3.97 \times 10^{5}\left[1.23 \times 10^{5} ; 8.62 \times 10^{5}\right]$ \\
\hline & $\mathrm{N}_{\mathrm{WP}}\left(\mathrm{T}_{\mathrm{WP}}\right)$ & $7.16 \times 10^{5}\left[6.64 \times 10^{4} ; 1.38 \times 10^{6}\right]$ & $4.97 \times 10^{5}\left[1.33 \times 10^{5} ; 1.28 \times 10^{6}\right]$ \\
\hline & $\mathrm{N}_{\mathrm{P}}\left(\mathrm{T}_{\mathrm{P}}\right)$ & $5.60 \times 10^{6}\left[5.43 \times 10^{5} ; 8.53 \times 10^{6}\right]$ & $2.44 \times 10^{6}\left[2.17 \times 10^{6} ; 2.53 \times 10^{6}\right]$ \\
\hline & $\mathrm{N}_{\mathrm{P}}\left(\mathrm{T}_{\mathrm{ANC}}\right)$ & n.a. & $1.85 \times 10^{5}\left[9.83 \times 10^{4} ; 2.17 \times 10^{5}\right]$ \\
\hline & $\mathrm{N}_{\mathrm{AWP}}\left(\mathrm{T}_{\mathrm{WP}}\right)$ & n.a. & $43[17 ; 121]$ \\
\hline & $\mathrm{N}_{\mathrm{LSP}}\left(\mathrm{T}_{\mathrm{SP}}\right)$ & n.a. & $147[52 ; 741]$ \\
\hline & $\mathrm{N}_{\mathrm{LWP}}\left(\mathrm{T}_{\mathrm{WP}}\right)$ & n.a. & $1.42 .10^{5}\left[2.65 \times 10^{4} ; 4.85 \times 10^{5}\right]$ \\
\hline & $\mathrm{N}_{\mathrm{SP}}\left(\mathrm{T}_{\mathrm{P}}\right)$ & n.a. & $43[35 ; 257]$ \\
\hline & $\mathrm{N}_{\mathrm{WP}}\left(\mathrm{T}_{\mathrm{P}}\right)$ & n.a. & $129[103 ; 974]$ \\
\hline \multirow{4}{*}{$\begin{array}{l}\text { Divergence time (in } \\
\text { generation) }\end{array}$} & $\mathrm{T}_{\mathrm{SP}}$ & n.a. & $69[35 ; 216]$ \\
\hline & $\mathrm{T}_{\mathrm{WP}}$ & $216[190 ; 1380]$ & $207[95 ; 526]$ \\
\hline & $\mathrm{T}_{\mathrm{P}}$ & $7.59 \times 10^{4}\left[6.90 \times 10^{3} ; 1.38 \times 10^{5}\right]$ & $560\left[448 ; 2.28 \times 10^{3}\right]$ \\
\hline & $\mathrm{T}_{\mathrm{ANC}}$ & n.a. & $9.05 .10^{5}\left[8.79 \times 10^{5} ; 1.10 \times 10^{6}\right]$ \\
\hline \multirow[t]{8}{*}{ Migration rate } & $\mathrm{m}(\mathrm{LSP} \rightarrow \mathrm{AWP})$ & n.a. & $5.36 \times 10^{-7}\left[2.95 \times 10^{-8} ; 9.38 \times 10^{-6}\right]$ \\
\hline & $\mathrm{m}(\mathrm{LWP} \rightarrow \mathrm{AWP})$ & n.a. & $5.15 \times 10^{-3}\left[1.62 \times 10^{-3} ; 1.04 \times 10^{-2}\right]$ \\
\hline & $\mathrm{m}(\mathrm{AWP} \rightarrow \mathrm{LSP})$ & n.a. & $2.40 \times 10^{-8}\left[2.67 \times 10^{-8} ; 9.86 \times 10^{-7}\right]$ \\
\hline & $\mathrm{m}(\mathrm{LWP} \rightarrow \mathrm{LSP})$ & n.a. & $9.69 \times 10^{-4}\left[3.10 \times 10^{-4} ; 1.91 \times 10^{-3}\right]$ \\
\hline & $\mathrm{m}(\mathrm{AWP} \rightarrow \mathrm{LWP})$ & n.a. & $4.29 \times 10^{-4}\left[4.91 \times 10^{-6} ; 1.10 \times 10^{-3}\right]$ \\
\hline & $\mathrm{m}(\mathrm{LSP} \rightarrow \mathrm{LWP})$ & n.a. & $1.11 \times 10^{-3}\left[3.46 \times 10^{-4} ; 2.53 \times 10^{-3}\right]$ \\
\hline & $\mathrm{m}(\mathrm{WP} \rightarrow \mathrm{SP})$ & n.a. & $2.29 \times 10^{-5}\left[2.34 \times 10^{-8} ; 2.55 \times 10^{-5}\right]$ \\
\hline & $\mathrm{m}(\mathrm{SP} \rightarrow \mathrm{WP})$ & n.a. & $8.72 \times 10^{-8}\left[2.99 \times 10^{-8} ; 8.50 \times 10^{-6}\right]$ \\
\hline \multirow[t]{6}{*}{ Growth rate } & $\mathrm{G}_{\mathrm{AWP}}$ & n.a. & $-0.480[-1.10 ;-0.174]$ \\
\hline & $\mathrm{G}_{\mathrm{LSP}}$ & n.a. & $-0.764[-1.89 ;-0.175]$ \\
\hline & $\mathrm{G}_{\mathrm{LWP}}$ & n.a. & $0.258\left[8.60 \times 10^{-2} ; 0.551\right]$ \\
\hline & $\mathrm{G}_{\mathrm{SP}}$ & n.a. & $-0.160\left[-0.201 ;-2.79 \times 10^{-2}\right]$ \\
\hline & $\mathrm{G}_{\mathrm{WP}}$ & n.a. & $-0.201[-0.247 ;-0.029]$ \\
\hline & $\mathrm{G}_{\mathrm{P}}$ & n.a. & $-2.46 \times 10^{-5}\left[-2.56 \times 10^{-5} ;-2.22 \times 10^{-5}\right]$ \\
\hline
\end{tabular}

